\title{
NATURAL GAS PRICES AND COAL DISPLACEMENT: EVIDENCE FROM ELECTRICITY MARKETS
}

\author{
Christopher R. Knittel \\ Konstantinos Metaxoglou \\ Andre Trindade \\ Working Paper 21627 \\ http://www.nber.org/papers/w21627
NATIONAL BUREAU OF ECONOMIC RESEARCH
1050 Massachusetts Avenue
Cambridge, MA 02138
October 2015

We thank Matt Barmack, Severin Borenstein, Jim Bushnell, Steve Cicala, Joe Cullen, Wayne Gray, Erin Mansur, Richard Schmalensee, Aaron Smith, Frank Wolak, Catherine Wolfram, the participants of the Spring 2014 Harvard seminar in Environmental Economics and Policy, and the 2014 NBER Environmental and Energy Economics Summer Institute for very helpful comments and suggestions. The views expressed herein are those of the authors and do not necessarily reflect the views of the National Bureau of Economic Research.

NBER working papers are circulated for discussion and comment purposes. They have not been peerreviewed or been subject to the review by the NBER Board of Directors that accompanies official NBER publications.

(C) 2015 by Christopher R. Knittel, Konstantinos Metaxoglou, and Andre Trindade. All rights reserved. Short sections of text, not to exceed two paragraphs, may be quoted without explicit permission provided that full credit, including (C) notice, is given to the source. 
Natural Gas Prices and Coal Displacement: Evidence from Electricity Markets

Christopher R. Knittel, Konstantinos Metaxoglou, and Andre Trindade

NBER Working Paper No. 21627

October 2015

JEL No. L5,L71,L94,Q4,Q5

\begin{abstract}
$\underline{\text { ABSTRACT }}$
We examine the environmental impact of the post-2005 natural gas glut in the United States due to the shale gas boom. Our focus is on quantifying short-term coal-to-gas switching decisions by different types of electric power plants in response to changes in the relative price of the two fuels. In particular, we study the following entities: investor-owned utilities (IOUs) and independent power producers (IPPs) in restructured markets coordinated by Independent System Operators, as well as IOUs in traditional vertically-integrated markets. Using alternative data aggregations and model specifications, we find that IOUs operating in traditional markets are more sensitive to changes in fuel prices than both IOUs and IPPs in restructured markets. We attribute our findings to differences in available gas-fired generating capacity with the most cost-efficient technology: electricity generators reduced their rate of investment in the restructured markets post restructuring. The heterogeneity in the response of fuel consumption to prices has implications for carbon dioxide $(\mathrm{CO} 2)$ emissions for the entities considered. Using simple back-of-the-envelope calculations, the almost 70\% drop in the price of natural gas between June 2008 and the end of 2012 translates to as much as 33\% reduction in $\mathrm{CO} 2$ emissions for IOUs in traditional markets, but only up to $19 \%$ for IOUs in restructured markets.
\end{abstract}

Christopher R. Knittel

MIT Sloan School of Management

100 Main Street, E62-513

Cambridge, MA 02142

and NBER

knittel@mit.edu

Konstantinos Metaxoglou

Carleton University

konstantinos.metaxoglou@ carleton.ca
Andre Trindade

Fundacao Getulio Vargas / EPGE

Praia de Botafogo, 190

Rio de Janeiro, RJ 22250-900 Brazil

andre.trindade@fgv.br 


\section{Introduction}

Fossil fuel-fired power plants burn coal, natural gas, or oil to generate electricity. In 2003, 51 percent of U.S. electricity was generated using coal, while 17 percent was generated using natural gas. By 2012, 37 percent of U.S. electricity was generated using coal, while 30 percent was generated using natural gas. One factor responsible for this change has been the change in the relative price of the two fuels. Recent advances in the ability to use hydraulic fracturing methods (fracking) have substantially increased natural gas production, altering the relative prices of natural gas and coal. ${ }^{1}$ On a per unit-of-energy basis, the average price of natural gas was nearly seven times the average price of coal at the beginning of 2006. By the end of 2012, this ratio had decreased to less than two.

Within the U.S. power sector, electricity generators vary in terms of their ownership structure and the type of market in which they operate. Following the large restructuring wave in the late 1990s and the early 2000s, wholesale electricity markets emerged in a large part of the country highlighted by the formation of independent system operators (ISOs) coordinating the function of some type of a power pool. ${ }^{2}$ In most cases, emphasis was put on the unbundling of generation from transmission and distribution, which gave rise to independent power producers (IPPs). IPPs focused exclusively on generation. The utilities continued to be responsible for transmission and distribution often engaging in generation. The parts of the country that did not opt for restructuring maintained the traditional structure of vertically integrated utilities. As a result, today, generation around the country is either utility or non-utility owned. Utilities, which may be publicly or investor owned, transmit and distribute electricity. Other than IPPs, large industrial and commercial entities serving almost exclusively their own needs, such as manufacturing plants, hospitals, and universities, own generation assets too.

This is the first paper showing that a generator's response to changes in the price of coal and natural gas depends on its ownership and the type of market in which it operates. ${ }^{3}$ We analyze the responses of investor-owned utilities (IOUs) and IPPs, which account for the largest fraction of the electric power sector in the country. Our analysis focuses on the period 2003-2012 and our interest lies exclusively on entities with both coal- and gas-fired

\footnotetext{
${ }^{1}$ Hausman and Kellogg (2015) offer an in-depth analysis of the welfare and distributional impacts of shale gas. See also the CBO (2014) study on the effects shale gas on energy markets, economic output, and the federal budget.

${ }^{2}$ See Borenstein and Bushnell (2015), on the status of the U.S. electricity industry after 20 years of restructuring.

${ }^{3}$ Recent related work, albeit with a different focus, on the effects of lower gas prices in electricity markets includes Brehm (2015), Cullen and Mansur (2014), Fell and Kaffine (2014), and Linn et al. (2014).
} 
generating capacity. The core of the empirical exercises analyzes the response of the share of gas in fuel consumption to the prices of coal and natural gas.

We find that IOUs in traditional markets respond more to fuel prices than both IOUs and IPPs in ISO markets. The results hold for both coal and natural gas prices and are robust to a set of alternative specifications that address potential econometric problems. We offer a plausible explanation for our findings: the restructuring process appears to have reduced the incentives of ISO market participants to invest in natural gas capacity, which limits their ability to respond to changes in the relative price of the two fuels. Using a differencein-differences exercise, we show that the natural gas capacity with the most cost-efficient technology increased more quickly in traditional markets compared to restructured markets post restructuring. We are not able to assess whether the relative increase in capacity in traditional markets was optimal as two competing effects may be at play. On one hand, restructuring may have led to lower investment due to market power. On the other hand, traditional markets may have invested more in capacity because of the Averch-Johnson effect.

The differences in the response of fuel consumption to prices has implications for carbon dioxide $\left(\mathrm{CO}_{2}\right)$ emissions for the entities considered. To illustrate this, we perform simple back-of-the-envelope calculations based on a model relating emissions to fuel prices. Based on our findings, the almost $70 \%$ drop in the price of natural gas between June 2008 and the end of 2012 translates to as much as a 33\% reduction in $\mathrm{CO}_{2}$ emissions for utilities in traditional markets, but only up to $19 \%$ for utilities in ISO markets. Eliminating the difference in responses to fuel prices between entities in traditional and ISO markets, also leads to significant gains in terms of lower $\mathrm{CO}_{2}$ emissions of up to 15 percentage points.

The remainder of the paper is organized as follows. We provide a background on natural gas and coal production, generation technologies, and wholesale electricity markets in Section 2. Section 3 contains a discussion of our data, our baseline results, and robustness checks regarding the heterogeneity in the response of fuel consumption to prices. Section 4 discusses our explanation of the findings and gives documental evidence supporting it. Section 5 presents our counterfactual emission calculations. We finally conclude. The tables and figures are attached at the end of the paper. An online Appendix is also provided. 


\section{Background}

\subsection{Natural gas and coal production}

The U.S. production of natural gas has increased considerably in the past 10 years. This increase is largely attributed to horizontal drilling - a technical innovation from the 1930sand multistage hydraulic fracturing (fracking), which began in the 1950s. The technique has allowed natural gas deposits captured in shale formations to be accessed. ${ }^{4}$ Data from the U.S. Energy Information Administration (EIA) for 2003-2012 show that monthly gross withdrawals of natural gas exhibit a clear upward trend, which is more pronounced after 2006. The withdrawals start at about 2 trillion cubic feet (tcf) in Jan-2003 and peak at around 2.6 tcf in late 2012. In 2007, gross withdrawals from shale gas accounted for approximately $7.5 \%$ of total gross withdrawals. By 2012, this fraction reached $35 \% .^{5}$

Panel (a) of Figure 3 shows the monthly natural gas price for the electric power sector using EIA data. ${ }^{6}$ After the frenzy of the commodity markets in the summer of 2008 , the series exhibits a largely declining pattern until mid-2012 when it starts bouncing back. Of course, for a good part of this period (fall 2008-fall 2009), the continued strong domestic production overlapped with sluggish demand due to the recession. Therefore, it is hard to tell how much of this decline was due to the positive (negative) shift in supply (demand). The last quarter of 2011 was the first time since the economic downturn that gas prices remained consistently below \$4/MMBtu (Macmillan et al. (2013)). The recovery of prices in the late 2012 has been attributed to an increased demand due to higher utilization of gasfired electric generating units (EGUs), the potential for additional LNG exports, inventory drawdowns as the country was marching towards a cold winter, and the diversion of rigs used in natural gas production towards the search of oil, among other factors.

According to EIA data for the 2003-2012 period, total U.S. coal production exhibits a slight upward trend between 2003 and 2009 and then starts declining with the Appalachia and Western regions driving much of the decline. The downward trend post 2009 is largely consistent with the slow recovery of the economy, the changing landscape of electric power

\footnotetext{
${ }^{4}$ The overall effect of fracking on the U.S. economy is pronounced. Hausman and Kellogg (2015) find that between 2007 and 2013 the shale gas revolution led to an increase in welfare for natural gas consumers and producers of $\$ 48$ billion per year. Newell and Raimi (2015) describe the major oil- and gas related revenues and costs for county and municipal governments have experienced in several states around the country. Cascio and Narayan (2015) study the effect of fracking on high-school dropouts. Muehlenbachs et al. (2014) using data from Pennsylvania and New York find negative impacts from shale gas development on nearby groundwater-dependent homes.

${ }^{5}$ http://www .eia.gov/dnav/ng/ng_prod_sum_dcu_NUS_a.htm.

${ }^{6}$ The electric power sector consists of utilities and IPPs only.
} 
generation towards higher utilization of gas-fired EGUs, and increasing stockpiles of coal at the power plants. The only good news for coal producers in the country during this period was the increase in exports, which have been historically served with Appalachian coal.

Panel (b) of Figure 3 shows the price of coal for the electric power sector from EIA for 2003-2012, which almost doubled during this period, from about $\$ 1.3 /$ MMBtu to around $\$ 2.5 /$ MMBtu. According to EIA, the price increases in 2008 were largely driven by the international markets where U.S. coal was in demand. An additional factor that affected coal prices was the escalating delivery cost due to the growing fuel surcharges added by transportation companies in response to the unprecedented rise in oil prices experienced during the first half of the year. ${ }^{7}$

Another difference between natural gas and coal, other than the patterns in production and prices discussed above, is the amount of pollution that they generate. Burning natural gas results in much fewer emissions of nearly all types of air pollutants and $\mathrm{CO}_{2}$ per unit of heat produced than coal. For example, 117 (over 200) lbs. of $\mathrm{CO}_{2}$ are produced per million British Thermal Units (MMBtu) of natural gas (coal). These clean burning properties have contributed to an increase in natural gas use for electricity generation and as a transportation fuel. ${ }^{8}$ When coal is burned, it releases impurities including sulfur, which when combined with oxygen forms sulfur dioxide $\mathrm{SO}_{2}$, that contributes to acid rain and respiratory illnesses. Other emissions resulting from coal combustion are: nitrogen oxides $\mathrm{NO}_{\mathrm{x}}$, particulates, mercury, and other heavy metals. ${ }^{9}$

\subsection{Natural gas and coal-fired electricity generation}

Both natural gas and coal are used in the generation of electricity with a combined share (gigawatt per day) of close to $70 \%$ in 2012. Between 2003 and 2012, there is a downward trend in the share of coal in electricity generation from $51 \%$ to $37 \%$. The share of natural gas in electricity generation, on the other hand, has nearly doubled during the same period; from $17 \%$ to $30 \% .^{10}$

The prices that power plants pay for the delivery of coal differ considerably due to the

\footnotetext{
${ }^{7}$ Our commentary here follows EIA (2008) and EIA (2009).

${ }^{8}$ http://www.eia.gov/energyexplained/index.cfm?page=natural_gas_environment.

${ }^{9}$ Additionally, when coal is burned at power plants, residues such as fly and bottom ash are created. In the past, fly ash was released into the air through the smoke stack, but by law much of it now must be captured by pollution control devices, like scrubbers. Fly ash is generally stored at coal power plants or placed in landfills. Pollution leaching from ash storage and landfills into groundwater has emerged as a new environmental concern. See http://www.eia.gov/energyexplained/index.cfm?page=coal_environment.

${ }^{10}$ See Table 3.1.A in EIA Electric Power Annual 2013.
} 
heterogeneity of the product and variations in the distance from the coal producing areas; transportation costs have historically been a major consideration in the choice of coal as a fuel. Coal-fired plants receive more than two thirds of their coal by rail and, while, on average, transportation costs account for approximately $20 \%$ of total delivered costs, they can be as high as $60 \%$ on shipments of coal originating in the Powder River Basin. ${ }^{11}$

By contrast, natural gas is a homogenous product. Since it is delivered by a national network of pipelines that maintain pressure throughout the grid, transportation costs are essentially zero. However, gas is harder to store in bulk near power plants, which makes them dependent on natural-gas pipelines that sometimes have delivery issues. In New England, for example, pipeline capacity has not kept up with the growth in natural-gas demand, which has led to increased volatility and numerous price spikes in the area recently. ${ }^{12}$

Most of the coal-fired plants in the U.S. are owned by traditional utilities with the Southeast and the Midwest portions of the country being the strongholds of coal-fired generation. They supply base load electricity and typically operate throughout the day due to low variable costs and performance penalties in transient operation. Pulverized-coal plants (PC) account for the great majority of existing coal-fired generating capacity in the U.S. Coal is ground to fine powder and injected through burners into the furnace with combustion air. The fine coal particles heat up rapidly, undergo pyrolysis and ignite. Pipes filled with water run through the burners and the heat turns the water to steam, which is used to rotate a turbine and generate electricity.

Gas-fired power plants employ three major technologies: steam boilers, combustion turbines also known as simple-cycle or gas turbines, and combined-cycle generators. The steam boiler technology is an older design that burns gas in a large boiler furnace to provide heat for turning water into steam. The steam is then run through a turbine that is attached to a generator, which spins and produces electricity. When a combustion turbine (CT) is put into operation, air is pulled in from outside and is compressed. This compressed air is ignited by burning natural gas and expands pushing the turbine much like steam does in a steam plant. The turbines then turn the electric generators. CTs are small, quick-start

\footnotetext{
${ }^{11}$ See http://www.eia.gov/coal/transportationrates/. Industry sources cite transportation costs as a major reason why many utilities in the New England states have chosen to generate electricity with natural gas, or import coal from overseas as a lower cost alternative.

${ }^{12}$ See http://www.eia.gov/naturalgas/issuesandtrends/deliverysystem/2013/. According to EIA, "Since 2012, limited supply from the Canaport and Everett (LNG) terminals coupled with congestion on the Tennessee and Algonquin pipelines has led to winter natural gas price spikes in New England. The problem continued in the winter of 2013-14, as indicated by New England's forward basis for January 2014 reaching \$17.41. Pipeline expansions could ease price spikes, but their cost-effectiveness, including their ultimate cost to consumers, remains a challenge."
} 
EGUs similar to aircraft jet engines. The natural gas combined cycle (NGCC) technology utilizes a gas turbine generator and a steam turbine that recovers waste heat from the gas turbine. The NGCC technology is the most efficient of the three and it is fair to say that it has revolutionized the industry.

Overall, gas-fired generation is more flexible than coal when it comes to changes in output and is the primary option to meet the variable portion of the electricity load and typically supplies peak power. However, the increased natural gas supply and relatively low natural gas prices, have resulted in more gas-fired EGUs being utilized to serve base load.

\subsection{Wholesale electricity markets}

Historically, the U.S. electric industry developed as a loosely connected structure of individual monopoly utility companies, each building and operating power plants and transmission and distribution lines to serve its franchise area. The utilities were overseen by regulators aiming to protect consumers from unfair pricing and other undesirable behavior.

In the 1990s, the federal government took a series of steps to restructure the wholesale electricity industry with an emphasis on the unbundling of generation from transmission and distribution. Efforts were also put on the promotion of competitive retail markets. For the first time in the history of the industry, retail customers in some states were given the choice to pick their power suppliers.

Twenty years later, electricity is sold either in traditional regulated markets in areas of the country that did not opt for restructuring, or in wholesale markets coordinated, initially, by Independent System Operators (ISOs), and, subsequently, by Regional Transmission Organizations (RTOs) in parts of the country that did (Figure 2). ISOs/RTOs use a series of forward and spot markets to make operational decisions, such as generator dispatch. Traditional systems rely on management to make those decisions, usually based on the cost of using the various generation options. Power trading occurs via bilateral transaction and transactions in ISO markets. ${ }^{13}$

Generation facilities around the country can also be classified as utility- or non-utility

\footnotetext{
${ }^{13}$ Electricity markets run by ISOs/RTOs deliver electricity through competitive market mechanisms. Although ISOs/RTOs have operational control of the transmission system, they do not own transmission or generation assets, perform the actual maintenance on generation or transmission equipment; or directly serve end use customers. More specifically, ISOs/RTOs use a series of markets to provide electric service to customers, which usually include the following: a forward (day-ahead or hour-ahead) energy market, a spot (real-time) energy market, capacity markets, which are designed to ensure resource adequacy, and ancillary-services (reserves) market. Bilateral transactions take place also in ISO/RTO markets. See FERC (2012) for additional details.
} 
owned. The main difference is that non-utilities do not transmit and do not distribute electricity. Utilities can be sub-classified into either investor-owned companies (IOUs) or public agencies. Our interest lies in the former. Non-utility-owned electric power plants belong to one of the following groups: independent power producers (IPPs), commercial, and industrial. Entities in the last two sectors produce electricity primarily for their own use and are outside the scope of the empirical analysis that follows.

The growth of non-utility ownership took off following the restructuring of the electricity industry and the divestiture of generation assets by utilities, especially, investor-owned utilities (IOUs) in the late 1990s. Those assets were transferred to another company or to an unregulated subsidiary with its own holding company structure. As a result, around the time of restructuring, the number of IOUs was decreasing, and non-utilities were expanding by buying utility divested generating assets, increasing their share of generation and new capacity. In the empirical analysis that follows, we will focus on the following three types of entities: IOUs in ISO/RTO markets, IOUs in traditional markets, and IPPs in ISO/RTO markets (Figure 1).

\section{Empirical analysis}

Our goal is to understand how entities with generation facilities adjust their use of inputs to changes in input prices, and how these responses vary by operator and market type. For this reason, we focus on two comparisons. The first comparison is between IOUs in traditional markets and IOUs in ISO markets. The second comparison is between IOUs in traditional markets and IPPs in ISO markets. By focusing on IOUs and IPPs, we capture the largest fraction of the U.S. electric power sector as defined by the EIA, since we only exclude publicly owned utilities.

\subsection{Data}

The vast majority of the data used in our analyses are publicly available from the EIA and the Environmental Protection Agency (EPA). We aggregate monthly data for net generation (MWh) from the EIA-906, EIA-920, and EIA-923 forms, at the plant level. Monthly data for total fuel consumption (electricity plus thermal output) in physical units and associated heat content (Btu) by fuel are available from the same forms. We also aggregate fuel consumption 
at the plant level. ${ }^{14}$

Monthly plant-level fuel receipts in physical units and delivery costs (\$/MMBtu) are publicly available from the FERC-423 and EIA-923 forms. The same forms contain information regarding the quality of fuel receipts (e.g., heat content). Although data on fuel receipts and associated heat content for IPPs are publicly available from the EIA-423 and EIA-923 forms, the associated delivery costs are not. For this reason, we obtained access to EIA confidential data. $^{15}$

We imputed plant-level fuel delivery costs that were not available for a particular month using fuel delivery costs from the closest plant that reported delivery costs during that month. Using the Haversine formula and power-plant coordinates, we identified the closest plant reporting delivery costs for imputation - we document the extent of imputation and comment on its implications below. One advantage of this method is that it accounts for unobserved factors that affect input costs and are spatially correlated. For the remainder of our discussion, we use the terms price and delivery cost interchangeably.

Annual data for nameplate operating capacity (MW) are available at the generator level from EIA-860. The form reports up to six energy sources for each generator. We use the primary energy source to construct a measure of operating nameplate capacity fired by coal and natural gas. For example, for a generator with operating nameplate capacity of 50MW for which the primary energy source is coal and the secondary source is natural gas, the coalfired nameplate operating capacity is $50 \mathrm{MW}$, while the natural gas-fired nameplate operating capacity is zero.

Using information from EIA-860, the EPA E-GRID 2012 database, and the proprietary SNL Financial Power Plant Database, we were able to check which plants in our sample fall within the footprint of the various ISOs. As an additional-albeit imperfect-check, we compared monthly total net generation and loads for 2007-2012 across six ISOs (CAISO,

\footnotetext{
${ }^{14}$ The Appendix in EIA (2013) provides a very informative and concise summary of the EIA and FERC forms used in our analysis.

${ }^{15}$ The FERC-423 form was filed by plants with a total steam turbine electric generating capacity and/or combined-cycle generating capacity of 50 or more megawatts. Only fuel delivered for use in steam-turbine and combined-cycle EGUs was reported. Fuel received for use in gas-turbine or internal-combustion EGUs that was not associated with a combined-cycle operation was not reported. In the case of EIA-923, Fuel receipts and costs are collected for plants with a nameplate capacity of 50MW or more and burn fossil fuels. The Form EIA 423 collected the cost and quality of fossil fuels to non-utility plants-IPPs and commercial and industrial combined heat and power producers with a nameplate capacity of 50MW or more. Using the databases described, we calculated annual generation, fuel consumption for electricity only in physical units, and fuel receipts in physical units, for coal and natural gas for the period 2001-2012. We then compared these annual figures with the corresponding ones in Tables Tables 3.1.a, 5.1.a, 5.4.a, and 7.2 in EIA (2013). The maximum percentage difference is around $5 \%$ and is associated with natural gas fuel receipts for years between 2008 and 2012 .
} 
ERCOT, ISO-NE, MISO, NYISO, PJM). The absolute value of their percentage difference never exceeded $5 \%{ }^{16}$

Annual information for environmental controls at the generator level are available from the EPA Air Markets Program Data (AMPD) database for facility attributes. The AMPD data contain also information on annual and ozone season (May-September) programs at the generator level. The annual programs include the Acid Rain program (ARP), the Transport Rule $\mathrm{NO}_{\mathrm{x}}$ Annual program (TRNOX), the Transport Rule $\mathrm{SO}_{2}$ Annual Group 1 program (TRSO2G1), the Transport Rule $\mathrm{SO}_{2}$ Annual Group 2 program (TRSO2G2), the CAIR SO2 (CAIRSO2), the CAIR $\mathrm{NO}_{\mathrm{x}}$ Annual program (CAIRNOX), and the Regional Greenhouse Gas Initiative (RGGI). The ozone season programs include the Transport Rule Ozone Season $\mathrm{NO}_{\mathrm{x}}$ program (TRNOXOS), the CAIR Ozone Season $\mathrm{NO}_{\mathrm{x}}$ program (CAIROS), the StateImplementation-Plan $\mathrm{NO}_{\mathrm{x}}$ program (SIPNOX), and the $\mathrm{NO}_{\mathrm{x}}$ Budget Program (NBP).

Finally, we obtained daily settlement $\mathrm{SO}_{2}$ and seasonal $\mathrm{NO}_{\mathrm{x}}\left(\mathrm{SNO}_{\mathrm{x}}\right)$ permit prices from Evolution Markets, an allowance broker we identified through EPA's website. ${ }^{17}$ It is worth mentioning that although the prices of the $\mathrm{SO}_{2}$ permits were constantly in the range $\$ 100$ $\$ 200 /$ ton during the first 10 years of the ARP, the situation changed when it became clear that more stringent caps would be put into place following CAIR in 2005. CAIR essentially required some states to reduce the amount of permits by two thirds, which increased substantially the price of the remaining allowances (Schmalensee and Stavins (2012)).

\subsection{Preliminary comparisons}

The summary statistics discussed below and the econometric analysis that follows are based on monthly data that we aggregate at the plant (Table 1) or at the firm (Table 2) level. ${ }^{18}$ The statistics pertain to a set of variables used in our formal econometric analysis regarding fuel consumption and emissions.

The statistics in all tables, as well as the results of the econometric analysis that follow, are based on samples that span the period 2003-2012 after filtering the data in a way that

\footnotetext{
${ }^{16}$ The date range is dictated by the fact that our current load data from SNL Energy don't extend before 2007. To our surprise, assigning plants to ISOs prior to 2010 (this is the first year for which the information is available in EIA-860) is rather difficult. For, example, although PJM provides a list of plants in its area, MISO informed us that treats such a list as confidential. FERC-714 would allow us to match exactly plants to ISOs but it has two problems: (i) it lacks EIA plant codes, (ii) its electronic filing started in 2005. Electricity imports to and exports from the ISO areas complicate the calculation even further.

${ }^{17}$ See http://www.epa.gov/airmarkets/trading/buying.html. Additional information about Evolution Markets is available at http://www.evomarkets.com/environment/emissions/_markets.

${ }^{18}$ We use the term firm to refer to the operator ID field in our data.
} 
allows us to focus on the within-entity consumption substitution patterns between coal and natural gas due to changes in their prices. We focus on dual-fuel entities; namely, plants and firms with both coal and gas firing at some point between 2003 and 2012. We provide additional details about the data in Appendix A.1. ${ }^{19}$

The first variable for which we report summary statistic and make comparisons across entities of interest is the share of fuel consumption in MMBtu from natural gas. The logarithm of this share will be the dependent variable in the first set of empirical models introduced below. Additionally, we include the fuel price (delivery cost) in dollars per MMBtu for coal and natural gas, as well as generation (MWh) and nameplate (MW) capacity. ${ }^{20}$ We also include a set of variables that appear as covariates in our econometric models. There are two main groups of variables here, both exhibiting variation only by year within a plant in the original data. The first group tracks the number of EGUs equipped with a particular pollution-abatement technology. The second group tracks the number of EGUs within a plant under the umbrella of an EPA program. ${ }^{21}$

\section{i. Plant-level comparisons}

There are roughly 4,100 observations associated with 44 plants in the case of traditional IOUs. We use about 6,850 observations and 68 plants in the case of ISO IOUs (Table 1). In both cases, we track a plant for roughly 8 years, on average. Traditional IOUs account for $40 \%$ of coal consumption and $56 \%$ of gas consumption when we focus on traditional and ISO IOUs. ${ }^{22}$ Traditional and ISO IOUs exhibit significant differences in coal prices paid, as well as in the number of units under the the Transport Rule $\mathrm{NO}_{\mathrm{x}}$ Annual program (TRNOX), the Transport Rule $\mathrm{SO}_{2}$ Annual Group 1 program (TRSO2G1), and the Transport Rule $\mathrm{SO}_{2}$ Annual Group 2 program (TRSO2G2). There are no other variables that exhibit significant differences at conventional levels.

We see around 4,700 observations for 58 plants in the case of IPPs. Therefore, we track an IPP's plant for roughly 7 years, on average. When we restrict the sample to traditional IOUs

\footnotetext{
${ }^{19}$ Overall, dual-fuel firms account for about $78 \%$ of coal consumption and coal-fired generation and for roughly $19 \%$ of the gas consumption and gas-fired generation. Dual-fuel plants account for about $37 \%$ of coal consumption and coal-fired generation and for roughly $5 \%$ of the gas consumption and gas-fired generation.

${ }^{20} \mathrm{We}$ use the sum of net generation and capacity from coal and natural gas only. Net generation includes generation used for the facility's own needs for both electricity and thermal output.

${ }^{21}$ When we aggregate the data at the firm level, the variables that pertain to the abatement technology and the EPA programs are based on the total number of EGUs operated by each firm.

${ }^{22}$ Five states (AL, MS, FL, GA, and SC) account for almost $83 \%$ of gas-fired generation by traditional IOUs. Five states (AL, CO, KY, FL, MS) account also for roughly $72 \%$ of coal-fired generation by traditional IOUs. MISO, PJM, and SPP account for almost the entirety of both coal- and gas-fired generation in the case of ISO IOUs.
} 
and IPPs, the former account for $46 \%$ of coal consumption and $80 \%$ of gas consumption. ${ }^{23}$ The number of EGUs with dry-lime scrubbers (FGDs), as well as the number of EGUs in the Acid Rain Program and the Transport Rule Annual Groups 1 and 2 are the variables that differ significantly between these two groups. We see borderline differences $(5.7 \%)$ for the gas share of fuel consumption, and the EGUs under the Transport Rule Annual and Seasonal (TRNOXOS) programs. Finally, the IPPs do pay more - on average, 7\% - than traditional IOUs for coal delivered to their plants, albeit the difference is significant at the $10 \%$ level.

\section{ii. Firm-level comparisons}

As Table 2 indicates, the number of observations associated with the traditional (ISO) IOUs is roughly $2,100(3,700)$. There is also a substantial difference in the number of firms in the two groups of interest; 24 for traditional and around 60 for ISO IOUs. Traditional IOUs account for $44 \%$ of coal consumption and $67 \%$ of gas consumption among the IOUs in our sample. ${ }^{24}$ The two groups of IOUs have similar characteristics. They only differ in a significant way ( $5 \%$ level) in terms of the coal prices (dollars per MMBtu), the average number of EGUs equipped with SCR technology, and the number of EGUs under the EPA TRNOXOS program. The fuel price differential could be attributed to the quality of coal (e.g., heat and sulfur content), to transportation costs, or to cost-reducing efforts in the restructured markets (see Cicala (2015)). There are no other variables that exhibit differences at conventional significance levels.

In the case of IPPs, we use about 2,800 observations for 68 firms. When we focus on traditional IOUs and ISO IPPs, traditional IOUs account for $55 \%$ of coal consumption and $76 \%$ of gas consumption. ${ }^{25}$ We see significant differences in the gas share of fuel consumption, generation, capacity, the average number of EGUs with SCR capabilities, and the number of EGUs under the ARP program. The gas share for traditional IOUs is almost three times its counterpart for the IPPs. Traditional IOUs generate almost twice as much as IPPs. They also have almost twice as much coal- plus gas-fired capacity. The values of the remaining variables for traditional IOUs are almost double the corresponding ones for IPPs. Most of the remaining variables also fail to exhibit significant differences at conventional levels

\footnotetext{
${ }^{23}$ Five states (AL, MS, FL, GA, and SC) account for about $83 \%$ of gas-fired generation by traditional IOUs. Five states (AL, MS, FL, GA, SC) account also for roughly $72 \%$ of coal-fired generation by traditional IOUs. ERCOT, MISO, and PJM account for almost the entirety of both coal- and gas-fired generation in the case of ISO IOUs.

${ }^{24}$ Five states (FL, AL, MS, AZ, GA) account for about $70 \%$ of gas-fired generation by traditional IOUs. Five states (GA, AL, NC, WY, FL) also account for roughly $70 \%$ of coal-fired generation by traditional IOUs. MISO, PJM, and SPP account for almost the entirety of both coal- and gas-fired generation in the case of ISO IOUs.

${ }^{25} \mathrm{ERCOT}$, MISO, and PJM account for almost all IPP coal- and gas-fired generation.
} 
between the two groups of interest.

Overall, the comparisons in Tables 1 and 2 provide fairly strong evidence that both plants and firms are similar on most observables. Of course, the major concern will be that they differ in terms of unobservables. We address the issue of time-invariant unobservables in the econometric models that follow.

\subsection{Baseline results}

We begin by examining the sensitivity of the natural-gas share of fuel consumption in MMBtu to coal and natural-gas prices in $\$ /$ MMBtu. Using $i$ to denote the cross-section and $t$ to denote the time (month), we estimate models of the form:

$$
\begin{array}{r}
\ln \left(s_{n g, i t}\right)=a+\beta_{n g} \ln \left(p_{n g, i t}\right)+\beta_{\text {coal }} \ln \left(p_{\text {coal }, i t}\right)+f\left(\text { lnetgen }_{i t} ; \beta_{f}\right) \\
+\mathbf{X}_{\mathbf{i t}}^{\prime} \beta_{x}+\eta_{i}+\eta_{m}+\varepsilon_{i t},
\end{array}
$$

Depending on the level of aggregation, the cross-section subscript $i$ denotes either a plant or a firm. Other than the logarithms of the fuel prices, $\ln \left(p_{\text {coal }, i t}\right)$, and $\ln \left(p_{\text {coal }, i t}\right)$, our specifications include plant or firm fixed effects $\left(\eta_{i}\right)$ to control for time-invariant characteristics and month fixed effects $\left(\eta_{m}\right)$ to account for seasonality in the share of natural gas. We also include a third-degree polynomial in the logarithm of net generation from the two fuels, $f\left(\right.$ lnetgen $\left._{i t}\right)$, to allow for flexibility in the output expansion path. The vector $\mathbf{X}_{i t}$ includes a number of covariates, which we have already discussed in the previous section, as well as $\mathrm{SO}_{2}$ and $\mathrm{NO}_{\mathrm{x}}$ permit prices. ${ }^{26}$

The complete list of covariates in our models is available in Table 3. We estimate all our models for dual-fuel firms and plants with data between 2003 and 2012. The logarithmic transformation of the natural gas share of fuel consumption is a very natural choice given that shares exhibit fairly skewed distributions. In addition, coupled with the logarithmic transformation of fuel prices, coefficients can be directly interpreted as elasticities.

The main testable hypothesis in our empirical exercises is whether entities in ISO markets respond differently from their counterparts in traditional markets including the controls

\footnotetext{
${ }^{26}$ The permit prices exhibit only monthly variation. Focusing on fuel use independent of other inputs, is equivalent to assuming that electricity production is Leontief in fuel and other inputs, which implies that a plant cannot substitute labor or materials for fuel. Note also that fuel accounts for more than $1 / 2$ of the total costs and around 3/4 of the operating costs of generating electricity (Bushnell and Wolfram (2005)).
} 
described above. To test this hypothesis, we pool data for entities in both traditional and ISO markets and interact all covariates in (1) except for the fixed effects with an ISO dummy that equals one if the entity under consideration falls within the footprint of one of the ISOs. As a result, our specification includes a long list of variables that would be hard to report due to space limitations. Hence, we only report the coefficient estimates and associated standard errors for fuel prices and their interaction with the ISO dummy in Table 4, which are the primary variables of interest.

Our modeling approach addresses the endogeneity of prices due to measurement error and buyer power. The measurement error is a (direct) implication of the imputation of fuel prices. Our original data do not contain cost information in numerous instances, such as those for plants without fuel receipts during a particular month. In these instances, we imputed monthly cost information from the closest (in terms of distance) plant. Buyer power that exhibits variation over time is a concern if, for example, larger plants or firms, are able to secure better prices. While classical measurement error generates an upward (towards zero) bias of the plants' response to prices, buyer power generates a downward (away from zero) bias.

We instrument both coal and gas prices using the coal and gas prices of other operators' nearest plant. ${ }^{27}$ Using data at the plant level, regressions of the fuel prices on the excluded instruments produce R-squared values between 0.36 (natural gas, traditional IOUs) and 0.94 (natural gas, ISO IPPs). The same regressions using data at the firm level produce R-squared values between 0.22 (natural gas, traditional IOUs) and 0.91 (natural gas, ISO IOUs). ${ }^{28}$

To account for endogeneity, we estimate linear IV (2SLS) models given the large dimension of the parameter vector and the small number of observations with shares having boundary values of one. As Table 3 indicates, there are 38 covariates (due to ISO dummy interactions) in our specifications setting aside plant or firm fixed effects, which add, at least, 58 more parameter estimates, depending on the level of aggregation and the groups of interest. Additionally, table 4 indicates that no more than 5 percent of the observations have share values of one depending on the model considered. ${ }^{29}$ The two rightmost columns of table 4

\footnotetext{
${ }^{27}$ For the models estimated using data at the firm level, we aggregate these prices using fuel purchases (physical units) as weights.

${ }^{28}$ Without imputation of the fuel delivery costs, the excluded instruments deliver R-squared values within the ranges reported here.

${ }^{29} \mathrm{IV}$ Tobit models produced highly similar estimates given the rather small number of observations for which the natural has share equals one. The use of Tobit models for data defined in the interval $[0,1]$ as opposed to being censored in the range $[0,1]$ has been questioned in the literature (see, e.g., Ramalho et al. (2011)). The estimation of fractional response models that account for both heterogeneity and endogeneity as in Papke and Wooldridge (2008) is challenging due to the high dimension of the parameter vector.
} 
indicate that imputation of prices is not an issue for either fuel with firm-level data. The imputation of fuel prices is quite substantial for plant-level data and affects 15\%-20\% of the observations depending on the groups of interest. In terms of inference, we cluster the standard errors by state, year, and month. ${ }^{30}$ Finally, as the last row of the table indicates, we strongly reject the null hypothesis of exogeneity of fuel prices in all four models using the regression-based test of Wooldridge (1989).

Based on our estimates using plant-level data, the price coefficients have the correct signs and are all highly significant. The fuel-consumption share of natural gas increases when the price of coal increases and decreases when the price of natural gas increases. The difference in responses to coal and gas prices between traditional and ISO entities are also statistically significant. ${ }^{31}$ With coefficient estimates of around -1.2 and standard errors in the neighborhood of 0.2 , the gas share seems to be inelastic for traditional IOUs and is not statistically different from zero for ISO IPPs and IOUs. ${ }^{32}$ In the case of coal, we see a highly significant elasticity of 1.7 for traditional IOUs, and elasticities of 0.53 and -0.17 for ISO IOUs and IPPs, respectively, which are statistically indistinguishable from zero. We discuss the remainder of the coefficient estimates not reported in Table 4 in Appendix A.2.

Using firm level-data, we also see price coefficients with the correct signs. However, they are statistically insignificant at conventional levels in two cases. The first is the interaction of the coal price with the ISO dummy when we compare traditional and ISO IOUs. The second is the interaction of the price for natural gas with the ISO dummy when we compare traditional IOUs and ISO IPPs. Therefore, we fail to reject the null hypothesis that the IPP response to natural gas prices is the same as that of traditional IOUs. An analogous statement holds in the case of the IOU response to coal prices. The natural gas price elasticity for traditional IOUs is about -1.1 in both cases with standard errors that are large enough so that we fail to reject the null that is different from -1. Its analog for the ISO entities is not different from zero. In the case of coal prices, we see highly significant elasticities of about 2.1 for traditional IOUs and around 1.7 for ISO IOUs. The coal price elasticity for the gas share of fuel consumption for ISO IPPs is statistically indistinguishable from zero. We follow the same approach with the plant-level estimates and discuss the coefficient estimates not reported in Table 4 in Appendix A.2.

\footnotetext{
${ }^{30}$ Clustering the standard errors by state and year increases the standard errors for the 8 coefficients of interest discussed below substantially. However, most of these coefficients remain statistically significant at $5 \%$.

${ }^{31}$ We use the shorthand traditional (ISO) entities to refer to entities in traditional (ISO) markets.

${ }^{32}$ Our conclusion for the response of ISO entities to natural gas prices is based on the sum of the appropriate coefficients and the associated standard error that requires a covariance term not reported in Table 4.
} 
Overall, using either plant- or firm-level data, we see that the gas share of fuel consumption for traditional IOUs is more responsive to gas prices than its counterpart for ISO IOUs and IPPs. However, the elasticity does not depart in a statistically significant way from unity in absolute value. The elasticities for ISO entities are statistically indistinguishable from zero. The million-dollar question is what drives the heterogeneity in responses to fuel prices. We postpone the answer accompanied with formal econometric analysis until the next section. ${ }^{33}$

\subsection{Robustness checks}

\section{i. Time trend}

In our baseline specifications we control for seasonality but exclude time trends because time is an important source of variation in prices that allows us to estimate accurately the response of fuel consumption to prices. That is particularly true for coal where the change in the delivery cost has increased at a steady rate similar to a linear trend (Figure 3). However, one may be concerned with the presence of omitted variables that change over time and are correlated with the fuel costs and the dependent variable. Controlling explicitly for a time trend mitigates those concerns.

In Table 5, we present results for our original specification augmented with a time trend. All four coefficients of interest have the correct signs and are significant using plant-level data. All four coefficients of interest have the correct signs using firm-level data, too. However, the coefficients on the interaction of the coal and gas prices with the ISO dummy are not significant when we compare traditional IOUs with ISO IOUs. The coefficient on the interaction of the gas price with the ISO dummy also fails to be statistically significant when we compare traditional IOUs with ISO IPPs.

ii Nearby plants only

Another potential concern in our baseline results is that we compare groups of plants or firms that are located in different parts of the country. In order to control for geographically correlated unobservable factors, we estimate a new set of IV models in Table 6 using plantlevel data only. In these models, we limit the samples to plants that are within 50 and 100 miles from each other.

\footnotetext{
${ }^{33}$ Our results that ISO IOUs don't seem to respond to changes in fuel prices are largely consistent with Fabrizio et al. (2007) who find that restructuring doesn't have a measurable impact on heat rates, but does have an effect on non-fuel costs. If reductions in fuel costs are quickly passed through to consumers, then ISO IOUs won't have an incentive to reduce heat rates or fuel costs, but would have an incentive to reduce labor costs.
} 
In the case of plants within 50 miles, all four coefficients of interest have the expected signs when we compare IOUs. This is not the case in the comparison of traditional IOUs with ISO IPPs. However, we have to keep in mind the small sample size. In this case, there are roughly 800 observations when we compare traditional with ISO IOUs and about 200 observations when we compare traditional IOUs with ISO IPPs. Expanding the set of neighboring plants to those within 100 miles gives a substantially larger number of observations. There are 2,300 observations when we compare IOUs and close to 1,500 observations when we compare traditional IOUs with ISO IPPs. The coefficients of interest have the expected signs for both sets of comparisons with the exception of the coefficient on the interaction of the coal price with the ISO dummy. The gas and coal price coefficients are highly significant when we compare traditional IOUs with ISO IPPs.

\section{Explaining response heterogeneity}

We now discuss one potential reason behind the notable differences in fuel-cost responses across entities in ISO and traditional markets; in doing so, we note that there may be others. We observe reductions in gas-fired capacity investment for the most cost-efficient technology (combined cycle) by ISO market participants relative to investment in traditional markets prior to the collapse in natural gas prices in the beginning of the shale gas era. This lower investment, we argue, led to two effects that limited the shift toward natural gas generation. First, fewer gas-fired EGUs are available in restructured markets to switch to if the price of natural gas relative to the price of coal falls. Second, existing gas-fired EGUs will be on average older and less efficient with higher heat rate, and, hence, less competitive compared to coal-fired EGUs. We find evidence in support of these two arguments.

First, using a difference-in-differences (DID) analysis of generating capacity, we show that entities in ISO markets have reduced their investment rates, post restructuring, compared to entities operating in traditional market. Second, we compare the distribution of natural gas heat rates across the different entities using firm-level data and we find that the distribution of heat rates in ISO markets compared to that of traditional markets is such that the latter group is, on average, more efficient (has lower heat rates). Finally, we discuss documental evidence claiming that the absence of long-term contracts in ISO markets may be responsible for this apparent lower investment and consequent inability to respond to fuel cost changes.

We do not claim that investment decisions in either market were more efficient than the other. Doing so is beyond the scope of this paper and would require a structural model 
of investment choices. However, we would like to raise the following points. On one hand, market power in restructured markets may have reduced investment incentives. ${ }^{34}$ On the other hand, investment incentives in traditional markets may be inefficiently large because of the Averch-Johnson effect.

\section{i. Difference-in-Differences Analysis}

Using $i$ to denote the state and $t$ to denote the year, we estimate the following model:

$$
\text { Capacity }_{n g, i t}=a+\beta \cdot \text { Rest }_{i t} \times \text { Post }_{i t}+\gamma \text { Consumption }_{i t}+\eta_{i}+\eta_{t}+\varepsilon_{i t} .
$$

The dependent variable in (2) is gas-fired operating combined-cycle nameplate capacity for 1990-2012 from EIA-860 data; see Table 8. ${ }^{35}$ We focus on the combined-cycle technology because it is the most competitive to coal due to its low heat rate. The most recent technologies achieve heat rates as low as 7,500 Btu/KWh, while the ones for coal-fired steam EGUs is close to $10,500 \mathrm{Btu} / \mathrm{KWh}$. Note also that the heat rate is the main driver of fuel cost that accounts for the largest fraction of variable costs for electricity generators. ${ }^{36}$

We construct the dependent variable using the gas-fired capacities of all entities in a state and not just IOUs or IPPs. In terms of notation, Rest ${ }_{i t}$ is a restructuring dummy based on Table 1 in Craig and Savage (2013). It equals one if state $i$ adopted an initiative that introduced competition in its wholesale electricity market, and zero, otherwise. In addition, Post $_{i t}$ equals one for the restructured states post restructuring and Consumption Cit $_{\text {is }}$ the state-level end-use electricity consumption (kilowatt hours). ${ }^{37}$ Finally, $\eta_{i}$ and $\eta_{t}$ are state and year fixed effects. In the remainder of our discussion, we refer to the states that restructured (did not restructure) as the treated (control) states.

Figure 4 shows the main trends in gas-fired combined-cycle capacity for the treated and the control states with time series plots of the mean nameplate capacity by year. Each point on the series is an average of the nameplate capacity across multiple states in a given year. The black vertical lines identify the time window during which the restructuring took place,

\footnotetext{
${ }^{34}$ For evidence of market power in restructured markets see Wolfram (1999), Borenstein et al. (2002), and Hortacsu and Puller (2008), among others. We also note that the existence of market may increase in investment incentives for entrants.

${ }^{35}$ We use operating nameplate capacity as defined by EIA.

${ }^{36}$ See http://www.eia.gov/electricity/annual/html/epa_08_02.html. The other types of gas-fired EGUs, steam and combustion turbines, achieve heat rates that are close to $10,500 \mathrm{Btu} / \mathrm{KWh}$ and 11,500 $\mathrm{Btu} / \mathrm{KWh}$, respectively.

${ }^{37}$ We use the column "Access to wholesale markets" of Table 1 in Craig and Savage to construct Rest ${ }_{i t}$. We use the year associated with the access to wholesale markets for each state to construct Post $t_{i t}$, which is also readily available in Craig and Savage.
} 
namely between 1997 and 2004. Table 7 provides some basic summary statistics regarding capacity for both the control and treated states.

An immediate observation from Figure 4 is the tremendous growth in gas-fired capacity associated with the combined-cycle technology, especially between the mid-1990s and the mid-2000s. However, after 2004, which marks the end of the restructuring wave and the beginning of the shale gas era, the growth is more notable for the control states - from about 5,500 MW to close to 8,000 MW on average. During the same period, the average gas-fired capacity increased from about 5,500 MW to around 6,000 MW, on average, in the treated states. The Southeast (Alabama, Florida, and Georgia) and the Southwest drive most of the increase in the control states. Texas, California, and the Midwest (to a lesser extent) drive most of the increase in the treated states.

Table 8 formalizes the comparison of mean gas-fired capacity with DID regression results based on equation (2) controlling for end-use electricity consumption, state, and year fixed effects. We report results for four alternative approaches to address the severe autocorrelation within state for two specifications. In column (1), we report OLS estimates with clustered standard errors by state. In column (2), we report the results for the Prais-Winsten estimator assuming an $\mathrm{AR}(1)$ autocorrelation structure that is common across states. In columns (3) and (4), we report results for a two-step feasible GLS (FGLS) estimator and an iterated FGLS estimator (I-FGLS) with AR(1) autocorrelation structures that also allow for crosssectional heteroskedasticity. In all 4 cases, we use almost 700 observations for the contiguous states.

The first thing to note in Table 8 is that the coefficient estimate of Rest $\times$ Post in the case of OLS is quite inefficient due to autocorrelation. Although OLS produces a larger point estimate than the 3 GLS procedures considered, it also produces a much larger standard error. The GLS estimates, however, are within the confidence interval of the OLS. The reader should also keep in mind that our interest lies on the qualitative nature of the results - the sign and not the magnitude of the coefficient - and the exercise should not be perceived as an attempt to evaluate the effects of restructuring on investment, which in itself is a very interesting topic. ${ }^{38}$

\footnotetext{
${ }^{38}$ We estimate (2) excluding observations for which the dependent variable equals zero because we estimated the same model using a log specification. Including the observations with zero values leads to coefficient estimates between $-1,050$ and -250 for Rest $\times$ Post. In this case, all coefficient estimates for Rest $\times$ Post are significant at $5 \%$ level except for OLS. The logarithmic specification produced a positive coefficient estimate for Rest $\times$ Post that can be explained as follows. Using $Y$ to denote the outcome variable, the logarithmic transformation amplifies the differences between the treated $(\mathrm{T})$ and control $(\mathrm{C})$ states before (B) 1997, $\left(Y_{B}^{T}-Y_{B}^{C}\right)$, and condenses the differences between the treated and control states after (A) $2004\left(Y_{A}^{T}-Y_{A}^{C}\right)$. As a result, the difference in differences, $\left(Y_{A}^{T}-Y_{A}^{C}\right)-\left(Y_{B}^{T}-Y_{B}^{C}\right)$, is positive despite
} 


\section{ii. Distribution of heat rates}

We study firm-level heat rates to measure the entities' efficiency, namely their ability to turn fuel consumption into electricity generation. The motivation behind the rather informal statistical analysis that follows is the fact that lower heat rates allow generators to respond more to natural gas prices all else equal. For example, assume generators $\mathrm{H}$ and L are both extra-marginal in the merit order in a world of high gas prices and are fully described by their heat rates and idle capacity. Both generators have the same idle capacity but generator $\mathrm{H}$ has a substantially higher heat rate than generator $\mathrm{L}$. There is a better chance that generator $\mathrm{L}$ will become infra-marginal if both generators are exposed to the same decrease in natural gas prices.

Figure 5 contains kernel density plots of natural gas heat rates (MMBtu/MWh) for the entities of interest using firm-level data. We have constructed these kernel density plots using the samples in Table 4 and excluding observations with heat rates below 7 and above 20. Panel (a) of Figure 5 compares the heat rate distributions of traditional and ISO IOUs. Panel (b) compares the heat rate distributions of traditional IOUs and ISO IPPs. Based on a cursory glance at the figure, the heat-rate distribution for traditional IOUs has a pronounced bimodal shape. Actually, it lies above its counterpart for the ISO IOUs for heat rates up to about 10.5 at which point the positions of the two kernel densities switch. In the case of panel (b), the "change-of-positions" point is somewhat lower at around 9.

Continuing in the spirit of a rather informal analysis, an OLS regression of heat rates on a constant and an ISO dummy produced intercepts around 10, and highly significant slopes of about 1.7 and 1.4, using the data in panels (a) and (b), respectively. Repeating the same regressions in logs produced intercepts around 2.2 and highly significant slopes of about 0.17 and 0.15 , respectively. Therefore, lower heat rates may offer another explanation for the fact that traditional IOUs respond more to gas prices than the ISO entities considered.

\section{iii. Documental evidence}

Additional support for our findings based on the difference-in-difference regressions comes from a report to the U.S. Congress by The Electric Energy Market Competition Task Force (2007), which was created by the Energy Policy Act of 2005. Among other activities, the

the fact that each of the two components is negative. The identifying assumptions in the DID framework are scale dependent; if they hold for the level of $Y$, they may not hold for monotone transformations of $Y$. In other words, the way we measure and transform the outcome variable is relevant for the plausibility of the identifying assumptions, even without postulating any parametric model for the relation of confounders and treatment to the outcomes, which has motivated the change-in-change estimator of Athey and Imbens (2006) - see page 155 in Meyer (1995) and page 437 in Athey and Imbens (2006). 
Task Force solicited comments from industry stakeholders on how competition policy affected investment decisions of both buyers and sellers in wholesale markets. In its executive summary, the Task Force concludes that investment in new generation exhibited significant variation across the country since the adoption of open access transmission and the introduction of competition in wholesale electricity markets. Additionally, the investment dampening effects of a perceived lack of long-term contracts for generation and transmission is also highlighted. The availability of long-term contracts was deemed to be critical to the ability of non-utility generators to secure capital for new investment.

This argument is largely in line with Joskow (2006), who makes the case that wholesale markets do not provide adequate incentives for the proper mix of generating capacity. According to Joskow, and drawing from the U.S. experience, a large part of the problem can be associated with the failure of wholesale spot markets to produce prices during periods of capacity constraints that are high enough to attract investment in a least-cost mix of generating capacity. The investment disincentives associated with high volatility in wholesale energy prices, limited hedging opportunities, and concerns about regulatory opportunism are also emphasized. Peak load plants, which tend to be gas plants, in particular, are more exposed to price risk due to their low capacity factors. Furthermore, there is the concern about strategic use of investment. Large incumbents, may choose to postpone generation investments to drive up prices from existing assets in the presence of barriers to entry that prevent new investment in generating capacity.

\section{Implications for emissions}

Our results based on the fuel consumption share of natural gas indicated heterogeneity in response to fuel prices for different types of generators with traditional IOUs being more responsive than both IOUs and IPPs in ISO markets. An obvious next step is to assess the implications of these differences on emissions of air pollutants, and, in, particular, on carbon dioxide $\left(\mathrm{CO}_{2}\right)$ emissions. To assess such implications, using $i$ to denote the plant or firm and $t$ to denote the month, we estimate models of the form:

$$
\begin{aligned}
\ln \left(C O 2_{i t}\right) & =a+\beta_{n g} \ln \left(P_{n g, i t}\right)+\beta_{\text {coal }} \ln \left(P_{\text {coal }, i t}\right)+\mathbf{X}_{\mathbf{i t}}^{\prime} \beta_{x}+\eta_{i}+\eta_{m}+\varepsilon_{i t} \\
C O 2_{i t} & \equiv C O 2_{n g, i t}+C O 2_{\text {coal }, i t},
\end{aligned}
$$

where $\mathrm{CO}_{2}$ is is the sum of $\mathrm{CO}_{2}$ emissions from coal and natural gas for the ith plant or firm depending on the level of aggregation. The specification in 3 is largely similar to the 
specification in 1, excluding the polynomial in generation.

Using data from the EPA Continuous Emissions Monitoring System (CEMS), aggregated at the plant- or firm-month level, we estimated the model in (3) using linear IV regressions with the fuel prices treated as endogenous. ${ }^{39}$ The instruments are the same as the ones used in the IV models for the gas share of fuel consumption. Once again, we capture heterogeneity by interacting all terms with the exception of plant/firm fixed effects with an ISO dummy. Our interest lies in the difference between traditional and ISO IOUs, as well as between traditional IOUs and ISO IPPs. ${ }^{40}$

Starting with the plant-level estimates in Table 9, the fuel price coefficients have the expected signs and are highly significant. An increase in the price of natural gas increases emissions due to substitution towards coal, which has almost double the $\mathrm{CO}_{2}$ emissions of natural gas. An increase in the price of coal has the opposite effect. Furthermore, emissions respond more to the price of coal than to the price of gas for all three groups. With the exception of coal prices in the case of the IOU comparisons at $10 \%$ level (column 1), the coefficients on the interactions of the fuel prices with the ISO dummy fail to be significant. Interestingly, in the case of coal, the emissions of ISO IOUs seem to be more responsive to prices than those for traditional IOUs. The elasticity of emissions with respect to the price of gas is 0.3 for traditional IOUs, 0.4 for ISO IOUs, and 0.3 for ISO IPPs. It is statistically significant at $1 \%$ in all three cases. The elasticity of emissions with respect to the price of coal is -0.6 for traditional IOUs, -0.9 for ISO IOUs, and -0.4 for ISO IPPs. It is also statistically significant at $1 \%{ }^{41}$

The results using firm-level data (columns 3 and 4) also produce fuel price coefficients with the expected signs. Once again, emissions respond more to coal prices than to gas prices. Although the coefficients of the interactions of the fuel prices with the ISO dummy fail to be significant, their size is very notable, and more so in the case of natural gas. They are about $40 \%$ of the magnitude of the gas price coefficient for the traditional IOUs and they play an important role in the back-of-the envelope (BOE) calculations discussed below. Furthermore, traditional IOUs respond similarly to changes in the price of both fuels, while ISO entities' response to coal prices is twice as large as their response to gas prices. The

\footnotetext{
${ }^{39}$ We use the primary fuel type of the generator reported in the CEMS data to calculate emissions due to coal and gas firing. Note that the EPA CEMS data are at the generating-unit level. EPA collects data on emissions for all EGUs burning fossil fuels and have capacity of at least $25 \mathrm{MW}$.

${ }^{40}$ Using either the Wu-Hausman test or Wooldridge's score test, we strongly reject the null of exogeneity for the four variables for the models reported in Table 9.

${ }^{41}$ Although not reported in Table 9, for the ISO entities, we calculate elasticities as the sum of the appropriate coefficient estimates and we calculate the proper standard errors taking into account their covariances. The same holds for the results using firm-level data discussed in the next paragraph.
} 
elasticity of emissions with respect to the price of gas is 0.52 for traditional IOUs, 0.30 for ISO IOUs, and 0.27 for ISO IPPs and is statistically significant at $1 \%$. The elasticity of emissions with respect to the price of coal is -0.49 for traditional IOUs and around -0.60 for ISO IOUs and IPPs; it is also statistically significant at $1 \%$.

Based on theses estimates, we perform a simple back-of-the-envelope (BOE) exercise in which we translate the drop in gas prices since mid-2008 to a drop in $\mathrm{CO}_{2}$ emissions from coal-plus-gas firing; see Figure 6. We first construct a monthly price index for natural gas between June 2008 and December 2012 using consumption-weighted fuel prices for the plants in our sample. In the spirit of a ceteris paribus exercise, we then translate the index of natural gas prices into an index of $\mathrm{CO}_{2}$ emissions using the coefficient estimates for natural gas in Table 9. For example, using the estimates in column (3) of Table 9, the $24 \%$ drop in the price of natural gas between June 2008 and August 2008 translates roughly into a 12\% (7\%) decrease in emissions for traditional (ISO) IOUs. $^{42}$

Using plant-level data, the level of emissions for traditional IOUs in December 2012 was at $79 \%$ of their June 2008 levels. The same number for ISO IOUs is $73 \%$ due to the positive coefficient of the interaction of gas prices with the ISO dummy in column (1) of Table 9. In the case of ISO IPPs, the emissions in December 2012 are at $81 \%$ of their levels in June 2008. With firm level data, traditional IOUs experience a decrease of $33 \%$ in their emissions relative to their June-2008 levels, while the ISO IOUs and IPPs experience a drop of $19 \%$ and $17 \%$, respectively.

In Figure 7, we provide actual and BOE hypothetical emissions eliminating the heterogeneity in responses to the price of natural gas in Table 9. That is, we set the interaction of the logarithm of the price of natural gas with the ISO dummy equal to zero. The dashed lines indicate $95 \%$ confidence intervals that have been constructed using non-parametric bootstrap drawing from the estimated residuals. The solid lines correspond to the means of the bootstrap distributions. ${ }^{43}$

Using plant-level data, the actual emissions in 2012 were at $82 \%$ of their level in 2008 when we focus on traditional and ISO IOUs. The BOE emissions are at about $65 \%$. The figures are largely similar when we focus on traditional IOUs and ISO IPPs. Had the ISO IPPs exhibited the same response to the price of natural gas as traditional IOUs, emissions would have dropped to $62 \%$ as opposed to $83 \%$ of their 2008 levels. Using firm-level data, the actual and BOE emission estimates are very similar to our estimates using plant-level data. We see gains of about 15 percentage points when we focus on IOUs (66\% vs. 81\%) and

\footnotetext{
${ }^{42}$ We calculate the decrease in emissions as follows: $0.5 \times 24 \%=12 \%$ and $(0.5-0.2) \times 24 \% \approx 7 \%$.

${ }^{43}$ Our bootstrap makes no correction for heteroskedasticity or clustering.
} 
around 16 percentage points in the case of traditional IOUs and ISO IPPs (62\% vs. $78 \%$ ).

\section{Conclusions}

We examine the environmental impact of the post-2005 natural gas glut caused by the shale gas boom on the U.S. electric power sector. We focus on short-term coal-to-gas switching decisions by different types of plants in response to changes in the relative price of the two fuels. We analyze investor-owned utilities (IOUs) and independent power producers (IPPs) in restructured electricity markets coordinate by Independent System Operators, and IOUs in traditional vertically-integrated markets. We find that IOUs operating in traditional markets are more sensitive to changes in fuel prices than both IOUs and IPPs in restructured markets. Our findings are robust to alternative model specifications data aggregations. We attribute the difference in responses to differences in available gas-fired capacity for the most costefficient technology based on formal econometric analysis and documental evidence. The heterogeneity in the response of fuel consumption to fuel prices has implications for the carbon dioxide $\left(\mathrm{CO}_{2}\right)$ emissions of the entities considered. The almost $70 \%$ drop in the price of natural gas between June 2008 and the end of 2012 translates to as much as $33 \%$ reduction in $\mathrm{CO}_{2}$ emissions for IOUs in traditional markets, but only up to $19 \%$ for IOUs in restructured markets. 


\section{References}

Athey, S. and G. Imbens (2006). Identification and inference in nonlinear difference-indifference models. Econometrica 74(2), 431-497.

Borenstein, B., J. Bushnell, and F. Wolak (2002). Measuring market inefficiencies in california's restructured wholesale electricity market. American Economic Review 92(5), 1376-1405.

Borenstein, S. and J. Bushnell (2015). The u.s. electricity industry after 20 years of restructuring. NBER WP 21113.

Brehm, P. (2015). Natural gas prices, electric generation investment, and greenhouse gas emissions. Working paper.

Bushnell, J. and C. Wolfram (2005). Ownership changes, incentives and plant efficiency: The divestiture of u.s. electric generation plants. CSEM WP 140.

Cascio, E. and A. Narayan (2015). Who needs a fracking education? the educational response to low-skill biased technological change? NBER WP 21359.

CBO (2014). The economics and budgetary effects of producing oil and natural gas from shale. Congressional Budget Office, Congress of the United States.

Cicala, S. (2015). When does regulation distort costs? lessons from fuel procurement in us electricity generation. American Economic Review 105(1), 411-444.

Craig, J. and S. Savage (2013). Market restructuring, competition and the efficiency of electricity generation: Plant-level evidence from the united states 1996 to 2006. Energy Journal 34(1), 1-31.

Cullen, J. and E. Mansur (2014). Inferring carbon abatement costs in electricity markets: A revealed preference approach using the shale revolution. NBER WP 20795.

EIA (2008). U.s coal supply and demand: 2008 review. Technical report, Energy Information Administration.

EIA (2009). U.s coal supply and demand: 2009 review. Technical report, Energy Information Administration.

EIA (2013). Electric power annual 2011. Technical report, Energy Information Administration. 
Fabrizio, K., N. Rose, and C. Wolfram (2007). Do markets reduce costs? assessing the impact of regulatory restructuring on us electric generation efficiency. American Economic Review 97(4), 1250-1277.

Fell, H. and D. Kaffine (2014). A one-two punch: Joint effects of natural gas abundance and renewables on coal-fired power plants. Colorado School of Mines WP 2014-10.

FERC (2012). Energy primer: A handbook of energy market basics. Technical report, Federal Energy Regulatory Commission.

Hausman, C. and R. Kellogg (2015). Welfare and distributional implications of shale gas. NBER WP 21115.

Hortacsu, A. and S. Puller (2008). Understanding strategic bidding in multi-unit auctions: A case study of the texas electricity spot market. RAND Journal of Economics 39(1), $86-114$.

Joskow, P. (1974). Inflation and environmental concern: Structural change in the process of public utility price regulation. Journal of Law and Economics 17(2), 291-327.

Joskow, P. (2006). Competitive electricity markets and investment in new generating capacity. MIT-CEEPR WP 06-009.

Linn, J., L. Muehlenbachs, and Y. Wang (2014). How do natural gas prices affect electricity consumers and the environment. Resources for the Future Discussion Paper 14-19.

Macmillan, S., A. Antonyuk, and H. Schwind (2013). Gas to coal competition in the u.s. power sector. Technical report, International Energy Agency (IEA).

Meyer, B. (1995). Jbes symposium on program and policy evaluation. Journal of Business and Economic Statistics 13(2), 151-161.

Muehlenbachs, L., E. Spiller, and C. Timmins (2014). The housing market impacts of shale gas development. NBER WP 19796.

Newell, R. and D. Raimi (2015). Shale public finance: Local government revenues and costs associated with oil and gas development. NBER WP 21542.

Papke, L. and J. Wooldridge (2008). Panel data methods for fractional response variables with an application to test pass rates. Journal of Econometrics 145, 121-123. 
Ramalho, E., J. Ramalho, and J. Murteira (2011). Alternative estimating and testing empirical strategies for fractional regression models. Journal of Economic Surveys 25(1), $19-68$.

Schmalensee, R. and R. Stavins (2012). The so2 allowance trading system: The ironic history of a grand policy experiment. MIT CEEPR Working Paper.

The Electric Energy Market Competition Task Force (2007). Report to congress on competition in wholesale and retail markets for electric energy. Pursuant to Section 1815 of the Energy Policy Act of 2005.

Wolfram, C. (1999). Measuring duopoly power in the british electricity spot market. American Economic Review 89(4), 803-826.

Wooldridge, J. (1989). Score diagnostics for linear models estimated by two stage least squares. In G. S. Maddala, P. Phillips, and T. Srinivasan (Eds.), Advances in Econometrics and Quantitative Economics: Essays in Honor of Professor C. R. Rao, pp. 66-87. Blackwell. 
Tables and Figures 
Table 1: Plant-level covariates

\begin{tabular}{|c|c|c|c|c|c|c|c|c|c|c|}
\hline \multirow{2}{*}{ Variables } & \multicolumn{2}{|c|}{ (1) } & \multicolumn{2}{|c|}{ (2) } & \multicolumn{2}{|c|}{ (3) } & \multicolumn{2}{|c|}{$(1)-(2)$} & $\begin{array}{r}\text { (1) } \\
\text { Trad IOUs } \\
\end{array}$ & $\begin{array}{l}\text { SO IPPs } \\
\text { SO }\end{array}$ \\
\hline & mean & sd & mean & $\mathrm{sd}$ & mean & $\mathrm{sd}$ & difference & $\mathrm{p}$-value & difference & $\mathrm{p}$-value \\
\hline NG share of fuel consumption & 0.115 & 0.234 & 0.105 & 0.255 & 0.056 & 0.179 & -0.009 & 0.802 & -0.059 & 0.057 \\
\hline Fuel delivery cost (NG) & $\$ 6.792$ & $\$ 3.428$ & $\$ 7.109$ & $\$ 3.087$ & $\$ 7.244$ & $\$ 3.119$ & $\$ 0.318$ & 0.253 & $\$ 0.452$ & 0.101 \\
\hline Fuel delivery cost (coal) & $\$ 2.306$ & $\$ 1.236$ & $\$ 1.844$ & $\$ 0.796$ & $\$ 2.058$ & $\$ 0.955$ & $-\$ 0.461$ & 0.006 & $-\$ 0.248$ & 0.167 \\
\hline Net generation (million MWh) & 0.340 & 0.368 & 0.286 & 0.279 & 0.303 & 0.340 & -0.055 & 0.423 & -0.037 & 0.617 \\
\hline Coal plus NG op. capacity & 894 & 711 & 730 & 587 & 712 & 706 & -164 & 0.233 & -183 & 0.228 \\
\hline \# of units with SCR & 0.564 & 1.236 & 0.480 & 0.887 & 0.447 & 0.897 & -0.084 & 0.711 & -0.117 & 0.622 \\
\hline \# of units with SNCR & 0.204 & 0.754 & 0.196 & 0.642 & 0.255 & 0.633 & -0.008 & 0.945 & 0.051 & 0.674 \\
\hline \# of units with dry-lime FGD & 0.255 & 0.607 & 0.093 & 0.364 & 0.040 & 0.266 & -0.162 & 0.108 & -0.215 & 0.028 \\
\hline \# of units with wet-lime FGD & 0.231 & 0.756 & 0.114 & 0.688 & 0.222 & 0.719 & -0.117 & 0.442 & -0.009 & 0.956 \\
\hline \# of units with PM controls & 0.529 & 0.954 & 0.451 & 0.904 & 0.537 & 1.048 & -0.078 & 0.676 & 0.008 & 0.971 \\
\hline \# of units in ARP & 3.803 & 2.568 & 3.173 & 1.650 & 2.668 & 2.057 & -0.630 & 0.173 & -1.135 & 0.025 \\
\hline \# of units in CAIRNOX & 1.789 & 2.902 & 1.272 & 1.979 & 1.384 & 2.204 & -0.518 & 0.099 & -0.405 & 0.228 \\
\hline \# of units in CAIROS & 1.475 & 2.692 & 1.223 & 2.015 & 1.340 & 2.169 & -0.251 & 0.417 & -0.135 & 0.676 \\
\hline \# of units in CAIRSO2 & 1.424 & 2.681 & 0.992 & 1.826 & 1.099 & 2.041 & -0.432 & 0.088 & -0.324 & 0.229 \\
\hline$\#$ of units in NBP & 0.988 & 2.397 & 0.930 & 1.965 & 1.963 & 2.373 & -0.058 & 0.860 & 0.975 & 0.006 \\
\hline \# of units in SIPNOX & & & & & 0.033 & 0.250 & & & 0.03 & 0.096 \\
\hline \# of units in TRNOX & 0.365 & 1.518 & 0.276 & 1.025 & 0.229 & 0.985 & -0.089 & 0.177 & -0.136 & 0.057 \\
\hline \# of units in TRNOXOS & 0.365 & 1.518 & 0.101 & 0.671 & 0.229 & 0.985 & -0.264 & 0.000 & -0.136 & 0.057 \\
\hline \# of units in TRSO2G1 & 0.073 & 0.673 & 0.218 & 0.959 & 0.189 & 0.886 & 0.145 & 0.002 & 0.116 & 0.019 \\
\hline \# of units in TRSO2G2 & 0.185 & 1.162 & 0.049 & 0.357 & 0.040 & 0.449 & -0.136 & 0.017 & -0.145 & 0.015 \\
\hline obs. & \multicolumn{2}{|c|}{4,086} & \multicolumn{2}{|c|}{6,842} & \multicolumn{2}{|c|}{4,705} & \multicolumn{2}{|c|}{10,928} & \multicolumn{2}{|c|}{8,791} \\
\hline \# plants & \multicolumn{2}{|c|}{44} & \multicolumn{2}{|c|}{68} & \multicolumn{2}{|c|}{58} & \multicolumn{2}{|c|}{112} & \multicolumn{2}{|c|}{102} \\
\hline
\end{tabular}

Note: The table contains the mean and standard deviation of the variables listed in the leftmost column for the three groups of interest: traditional investor-owned utilities (IOUs), IOUs in ISO/RTO markets, and independent power producers (IPPs) in ISO/RTO markets. The two rightmost columns contain the differences in means and associated p-values. The variables are discussed in Section 3.1 of the main text. The p-values are calculated using std.errors clustered by plant. 
Table 2: Firm-level covariates

\begin{tabular}{|c|c|c|c|c|c|c|c|c|c|c|}
\hline \multirow{2}{*}{ Variables } & \multicolumn{2}{|c|}{ (1) } & \multicolumn{2}{|c|}{ (2) } & \multicolumn{2}{|c|}{ (3) } & \multicolumn{2}{|c|}{$(1)-(2)$} & \multicolumn{2}{|c|}{$\begin{array}{c}\text { (1)-(3) } \\
\text { Trad IOUs-ISO IPPs }\end{array}$} \\
\hline & mean & sd & mean & sd & mean & sd & difference & p-value & difference & $\mathrm{p}$-value \\
\hline NG share of fuel consumption & 0.184 & 0.193 & 0.108 & 0.165 & 0.063 & 0.153 & -0.076 & 0.064 & -0.120 & 0.003 \\
\hline Fuel delivery cost (NG) & $\$ 6.666$ & $\$ 3.003$ & $\$ 6.765$ & $\$ 2.838$ & $\$ 7.215$ & $\$ 3.247$ & $\$ 0.098$ & 0.760 & $\$ 0.549$ & 0.125 \\
\hline Fuel delivery cost (coal) & $\$ 2.347$ & $\$ 1.106$ & $\$ 1.802$ & $\$ 0.644$ & $\$ 2.135$ & $\$ 0.939$ & $-\$ 0.544$ & 0.011 & $-\$ 0.212$ & 0.349 \\
\hline Net generation (million MWh) & 1.770 & 1.684 & 1.141 & 0.876 & 0.936 & 0.967 & -0.628 & 0.101 & -0.833 & 0.032 \\
\hline Coal plus NG op. capacity & 4,678 & 3,868 & 3,234 & 2,309 & 2,478 & 2,675 & $-1,444$ & 0.113 & $-2,200$ & 0.019 \\
\hline \# of units with SCR & 4.627 & 5.173 & 1.932 & 2.490 & 1.776 & 2.496 & -2.695 & 0.020 & -2.850 & 0.013 \\
\hline \# of units with SNCR & 0.837 & 2.585 & 0.557 & 1.717 & 1.106 & 1.850 & -0.280 & 0.607 & 0.269 & 0.605 \\
\hline \# of units with dry-lime FGD & 0.846 & 1.717 & 0.348 & 1.211 & 0.113 & 0.511 & -0.497 & 0.262 & -0.733 & 0.064 \\
\hline \# of units with wet-lime FGD & 1.207 & 2.353 & 0.374 & 1.185 & 0.600 & 1.486 & -0.833 & 0.078 & -0.608 & 0.196 \\
\hline \# of units with PM controls & 1.963 & 3.377 & 1.138 & 1.997 & 1.066 & 1.536 & -0.825 & 0.327 & -0.897 & 0.265 \\
\hline \# of units in ARP & 19.000 & 13.580 & 13.240 & 8.804 & 9.294 & 8.147 & -5.761 & 0.070 & -9.705 & 0.002 \\
\hline \# of units in CAIRNOX & 11.120 & 19.040 & 6.902 & 10.690 & 6.378 & 12.440 & -4.222 & 0.182 & -4.746 & 0.156 \\
\hline$\#$ of units in CAIROS & 9.412 & 16.920 & 6.544 & 10.790 & 5.053 & 10.970 & -2.867 & 0.327 & -4.359 & 0.147 \\
\hline \# of units in CAIRSO2 & 8.891 & 17.530 & 5.386 & 9.878 & 4.954 & 11.230 & -3.505 & 0.165 & -3.937 & 0.138 \\
\hline$\#$ of units in NBP & 3.275 & 9.567 & 3.629 & 9.319 & 6.379 & 12.240 & 0.354 & 0.828 & 3.104 & 0.077 \\
\hline \# of units in SIPNOX & & & & & 0.059 & 0.385 & & & 0.06 & 0.209 \\
\hline \# of units in TRNOX & 2.040 & 9.002 & 1.505 & 5.612 & 1.069 & 5.513 & -0.535 & 0.376 & -0.970 & 0.124 \\
\hline \# of units in TRNOXOS & 2.040 & 9.002 & 0.637 & 3.814 & 1.064 & 5.451 & -1.403 & 0.019 & -0.975 & 0.121 \\
\hline \# of units in TRSO2G1 & 0.586 & 4.320 & 1.183 & 5.237 & 0.732 & 4.414 & 0.597 & 0.143 & 0.146 & 0.705 \\
\hline \# of units in TRSO2G1 & 0.691 & 5.608 & 0.285 & 2.149 & 0.337 & 3.378 & -0.406 & 0.330 & -0.353 & 0.439 \\
\hline obs. & \multicolumn{2}{|c|}{2,075} & \multicolumn{2}{|c|}{3,659} & \multicolumn{2}{|c|}{2,795} & \multicolumn{2}{|c|}{5,734} & \multicolumn{2}{|c|}{4,870} \\
\hline \# firms & \multicolumn{2}{|c|}{24} & \multicolumn{2}{|c|}{58} & \multicolumn{2}{|c|}{68} & \multicolumn{2}{|c|}{82} & \multicolumn{2}{|c|}{92} \\
\hline
\end{tabular}

Note: The table contains the mean and standard deviation of the variables listed in the leftmost column for the three groups of interest: traditional investor-owned utilities (IOUs), IOUs in ISO/RTO markets, and independent power producers (IPPs) in ISO/RTO markets. The two rightmost columns contain the differences in means and associated p-values. The variables are discussed in Section 3.1 of the main text. The p-values are calculated using std.errors clustered by firm. 
Table 3: Variables used in linear IV models for the natural gas share of fuel consumption

\begin{tabular}{ll}
\hline \hline & Variables \\
\hline $\log$ coal delivery cost & \# of units with PM controls \\
$\log$ NG delivery cost & \# of units in ARP \\
$\log$ net generation & \# of units in CAIRNOX \\
$\log$ net generation sq. & \# of units in CAIROS \\
log net generation cb. & \# of units in CAIRSO2 \\
coal plus NG op. capacity & \# of units in NBP \\
SO2 permit price & \# of units in SIPNOX \\
SNOX permit price & \# of units in TRNOX \\
\# of units with SCR & \# of units in TRNOXOS \\
\# of units with SNCR & \# of units in TRSO2G1 \\
\# of units with dry-lime FGD & \# of units in TRSO2G2 \\
\# of units with wet-lime FGD & \\
\hline
\end{tabular}

Note: The table contains the list of the explanatory variables in the linear IV models for the natural gas share of fuel consumption as discussed in Section 3.3 of the main text. The list excludes the appropriate fixed effects and the variable interactions with the ISO dummy that equals one if the variable pertain to entities participating in ISO/RTO wholesale markets, and zero otherwise. 
Table 4: Linear IV model for the natural gas share of fuel consumption, baseline

\begin{tabular}{|c|c|c|c|c|}
\hline \multirow[t]{3}{*}{ Variable } & \multicolumn{2}{|c|}{ Plant } & \multicolumn{2}{|c|}{ Firm } \\
\hline & (1) & (2) & (3) & (4) \\
\hline & IOUs & IOUs/IPPs & IOUs & IOUs/IPPs \\
\hline \multirow[t]{2}{*}{$\log N G$} & $-1.2172 * * *$ & $-1.2172 * * *$ & $-1.1181 * * *$ & $-1.1181 * * *$ \\
\hline & $(0.2088)$ & $(0.2088)$ & $(0.3343)$ & $(0.3343)$ \\
\hline \multirow[t]{2}{*}{$\log \mathrm{NG} \times \mathrm{ISO}$} & $1.2368 * * *$ & $1.3259 * * *$ & $0.8063 * *$ & 0.4602 \\
\hline & $(0.2518)$ & $(0.2721)$ & $(0.3963)$ & $(0.4198)$ \\
\hline \multirow[t]{2}{*}{$\log$ coal } & $1.7297 * * *$ & $1.7297 * * *$ & $2.0842 * * *$ & $2.0842 * * *$ \\
\hline & $(0.2621)$ & $(0.2621)$ & $(0.3358)$ & $(0.3358)$ \\
\hline \multirow[t]{2}{*}{$\log$ coal $\times$ ISO } & $-1.2009 * * *$ & $-1.8999 * * *$ & -0.4286 & $-2.3670 * * *$ \\
\hline & $(0.3557)$ & $(0.3714)$ & $(0.6299)$ & $(0.5588)$ \\
\hline All obs. & 10,928 & 8,791 & 5,734 & 4,870 \\
\hline Boundary obs. & 564 & 244 & 17 & 21 \\
\hline Imputed coal obs. & 1,752 & 1,312 & 0 & 0 \\
\hline Imputed NG obs. & 1,823 & 1,722 & 0 & 0 \\
\hline Cross section & 44 & 44 & 24 & 24 \\
\hline Cross section ISO & 68 & 58 & 58 & 68 \\
\hline Exogeneity test & $11.92 * * *$ & $8.205 * * *$ & $11.32 * * *$ & $10.67 * * *$ \\
\hline
\end{tabular}

Note: In the top panel of the table, we report 2SLS estimates using both plant-level (Plant) and firm-level data (Firm) for the baseline model in Section 3.3 of the main text. We use log NG (coal) to denote the logarithm of the natural gas (coal) price. We use log NG (coal) $\times$ ISO, to denote the interaction of the logarithm of natural gas (coal) price with a dummy that equals one if the entities indicated in columns (1)-(4) participate in ISO/RTO wholesale markets, and zero otherwise. The standard errors in parentheses are clustered by state, year, and month. In the bottom panel of the table, we report the number of observations for which the share of natural gas equals one (Boundary obs.), the number of observations for which we impute coal and natural gas prices, as well as the number of plants/firms in traditional (Cross section) and ISO/RTO markets (Cross section ISO). The asterisks denote statistical significance at $1 \%(* * *), 5 \%(* *)$, and $10 \%(*)$, respectively. 
Table 5: Linear IV models for the natural gas share of fuel consumption, time trend

\begin{tabular}{|c|c|c|c|c|}
\hline \multirow[t]{3}{*}{ Variable } & \multicolumn{2}{|c|}{ Plant } & \multicolumn{2}{|c|}{ Firm } \\
\hline & (1) & (2) & (3) & (4) \\
\hline & IOUs & IOUs/IPPs & IOUs & IOUs/IPPs \\
\hline \multirow[t]{2}{*}{$\log N G$} & $-1.2903 * * *$ & $-1.2903 * * *$ & $-2.8072 * *$ & $-2.8073 * *$ \\
\hline & $(0.2126)$ & $(0.2126)$ & (1.1986) & $(1.1986)$ \\
\hline \multirow[t]{2}{*}{$\log \mathrm{NG} \times \mathrm{ISO}$} & $1.3134 * * *$ & $1.4650 * * *$ & $2.3791 *$ & $2.2616^{*}$ \\
\hline & $(0.2546)$ & $(0.2788)$ & (1.2329) & $(1.2255)$ \\
\hline \multirow[t]{2}{*}{$\log$ coal } & $2.5852 * * *$ & $2.5852 * * *$ & $9.0109 * *$ & $9.0113 * *$ \\
\hline & $(0.7766)$ & $(0.7766)$ & $(3.6980)$ & $(3.6981)$ \\
\hline \multirow[t]{2}{*}{$\log$ coal $\times$ ISO } & $-2.2391 * *$ & $-3.2984 * * *$ & -4.8355 & $-10.4845^{* * *}$ \\
\hline & $(1.1147)$ & $(0.8742)$ & $(5.5976)$ & $(3.8303)$ \\
\hline All obs. & 10,928 & 8,791 & 5,734 & 4,870 \\
\hline Boundary obs. & 564 & 244 & 17 & 21 \\
\hline Imputed coal obs. & 1,752 & 1,312 & 0 & 0 \\
\hline Imputed NG obs. & 1,823 & 1,722 & 0 & 0 \\
\hline Cross section & 44 & 44 & 24 & 24 \\
\hline Cross section ISO & 68 & 58 & 58 & 68 \\
\hline Exogeneity test & $6.987 * * *$ & $4.901 * * *$ & $7.141 * * *$ & $7.296 * * *$ \\
\hline
\end{tabular}

Note: In the top panel of the table, we report 2SLS estimates using both plant-level (Plant) and firm-level data (Firm) for the model with time trend in Section 3.4 of the main text. We use log $\mathrm{NG}$ (coal) to denote the logarithm of the natural gas (coal) price. We use log NG (coal) $\times$ ISO, to denote the interaction of the logarithm of natural gas (coal) price with a dummy that equals one if the entities indicated in columns (1)-(4) participate in ISO/RTO wholesale markets, and zero otherwise. The standard errors in parentheses are clustered by state, year, and month. In the bottom panel of the table, we report the number of observations for which the share of natural gas equals one (Boundary obs.), the number of observations for which we impute coal and natural gas prices, as well as the number of plants/firms in traditional (Cross section) and ISO/RTO markets (Cross section ISO). The asterisks denote statistical significance at $1 \%(* * *), 5 \%(* *)$, and $10 \%(*)$, respectively. 
Table 6: Linear IV models for the natural gas share of fuel consumption, neighboring plants only

\begin{tabular}{|c|c|c|c|c|}
\hline \multirow[t]{3}{*}{ Variable } & \multicolumn{2}{|c|}{ Plant-50 miles } & \multicolumn{2}{|c|}{ Plant-100 miles } \\
\hline & (1) & (2) & (3) & (4) \\
\hline & IOUs & IOUs/IPPs & IOUs & IOUs/IPPs \\
\hline \multirow[t]{2}{*}{$\log N G$} & $-2.8937 * *$ & 0.1163 & -1.7217 & $-2.6362 * * *$ \\
\hline & $(1.4758)$ & $(5.3443)$ & $(1.5244)$ & $(0.7914)$ \\
\hline \multirow[t]{2}{*}{$\log \mathrm{NG} \times \mathrm{ISO}$} & $3.7679 * *$ & -0.9117 & 2.2309 & 1.2874 \\
\hline & $(1.6337)$ & (5.7179) & $(1.5541)$ & (1.9794) \\
\hline \multirow[t]{2}{*}{$\log$ coal } & 3.5994 & -1.8795 & 6.5424 & $8.1737 * * *$ \\
\hline & (2.4159) & $(7.2882)$ & $(4.5103)$ & $(2.5112)$ \\
\hline \multirow[t]{2}{*}{$\log \operatorname{coal} \times \mathrm{ISO}$} & -3.1969 & 1.6898 & -5.8518 & 11.2336 \\
\hline & $(2.8249)$ & $(5.6636)$ & $(4.5294)$ & $(25.1433)$ \\
\hline All obs. & 813 & 213 & 2,300 & 1,481 \\
\hline Censored obs. & 0 & 0 & 27 & 6 \\
\hline Imput. coal obs. & 17 & 47 & 200 & 187 \\
\hline Imput. NG obs. & 56 & 48 & 348 & 259 \\
\hline Cross section & 2 & 1 & 6 & 6 \\
\hline Cross section ISO & 11 & 2 & 32 & 22 \\
\hline Exogeneity test & $3.02 * * *$ & $4.501 * * *$ & $6.029 * * *$ & $4.059 * * *$ \\
\hline
\end{tabular}

Note: In the top panel of the table, we report 2SLS estimates using using plants within 50 and 100 miles for the model with neighboring plants only in Section 3.4 of the main text. We use log NG (coal) to denote the logarithm of the natural gas (coal) price. We use log NG (coal) $\times$ ISO, to denote the interaction of the logarithm of natural gas (coal) price with a dummy that equals one if the entities indicated in columns (1)-(4) participate in ISO/RTO wholesale markets, and zero otherwise. The standard errors in parentheses are clustered by state, year, and month. In the bottom panel of the table, we report the number of observations for which the share of natural gas equals one (Boundary obs.), the number of observations for which we impute coal and natural gas prices, as well as the number of plants/firms in traditional (Cross section) and ISO/RTO markets (Cross section ISO). The asterisks denote statistical significance at 1\%(***), 5\%(**), and $10 \%(*)$, respectively. 
Table 7: State-level combined-cycle gas-fired capacity statistics

\begin{tabular}{|c|c|c|c|c|}
\hline & (1) & (2) & (3) & (4) \\
\hline \multirow[t]{2}{*}{ Statistic } & Control & Treated & Treated & Treated \\
\hline & & All & Pre-Rest. & Post-Rest. \\
\hline mean & 4,213 & 3,428 & 616 & 4,770 \\
\hline std.dev. & 5,523 & 6,181 & 1,166 & 7,089 \\
\hline median & 2,573 & 1,377 & 194 & 2,697 \\
\hline obs. & 178 & 489 & 158 & 331 \\
\hline
\end{tabular}

Note: We use Control (Treated) to denote the states that restructured (did not restructure) their wholesale electricity markets. Columns (3) and (4) contain summary statistics for the treated states pre- and post-restructuring. For additional details, including the definition of restructuring, see the discussion in Difference-in-Differences Analysis in Section 4 of the main text.

Table 8: State-level difference-in-differences analysis for combined-cycle gas-fired capacity

\begin{tabular}{lcccc}
\hline \hline & $(1)$ & $(2)$ & $(3)$ & $(4)$ \\
& OLS & PW & FGLS & I-FGLS \\
\cline { 2 - 5 } TREAT $\times$ POST & $-1,576.9470^{*}$ & $-909.3138^{* * *}$ & $-335.0440^{* *}$ & $-229.1362^{* * *}$ \\
& $(865.4763)$ & $(273.8900)$ & $(162.8444)$ & $(80.2367)$ \\
\hline End-use cons. & YES & YES & YES & YES \\
State FE & YES & YES & YES & YES \\
Year FE & YES & YES & YES & YES \\
\hline Obs. & 667 & 667 & 667 & 667 \\
\# States & 38 & 38 & 38 & 38 \\
\# States Treated & 28 & 28 & 28 & 28 \\
\hline
\end{tabular}

Note: We use TREAT $\times$ POST to denote the variable Rest $\times$ Post in equation 2 of Section 4 in the main text. The lower part of each panel indicates whether we control for state-level enduse electricity consumption (End-use cons.), state, and year fixed effects. The column headers PW, FGLS, and IFGLS denote the Prais-Winsten, feasible GLS, and iterated feasible GLS estimators we employed. The asterisks denote statistical significance at $1 \%(* * *), 5 \%(* *)$, and $10 \%(*)$, respectively. 
Table 9: Linear IV models of $\mathrm{CO}_{2}$ emissions

\begin{tabular}{|c|c|c|c|c|}
\hline & \multicolumn{2}{|c|}{ Plant } & \multicolumn{2}{|c|}{ Firm } \\
\hline & (3) & (4) & (1) & (2) \\
\hline & IOUs & IOUs/IPPs & IOUs & IOUs/IPPs \\
\hline \multirow[t]{2}{*}{$\log N G$} & $0.3020 * * *$ & $0.3020 * * *$ & $0.5259 * * *$ & $0.5259 * * *$ \\
\hline & $(0.0783)$ & $(0.0783)$ & $(0.1208)$ & $(0.1208)$ \\
\hline \multirow[t]{2}{*}{$\log \mathrm{NG} \times \mathrm{ISO}$} & 0.0953 & -0.0296 & -0.2295 & $-0.2584 *$ \\
\hline & $(0.1249)$ & $(0.1132)$ & $(0.1436)$ & $(0.1540)$ \\
\hline \multirow[t]{2}{*}{$\log$ coal } & $-0.5886 * * *$ & $-0.5886 * * *$ & $-0.4929 * * *$ & $-0.4929 * * *$ \\
\hline & $(0.1281)$ & $(0.1281)$ & $(0.1023)$ & $(0.1023)$ \\
\hline \multirow[t]{2}{*}{$\log$ coal $\times$ ISO } & $-0.3504 *$ & 0.1489 & -0.1231 & -0.1099 \\
\hline & $(0.1839)$ & $(0.2017)$ & $(0.1641)$ & $(0.2148)$ \\
\hline Observations & 11,923 & 9,223 & 5,733 & 4,623 \\
\hline R-squared & 0.75 & 0.79 & 0.94 & 0.93 \\
\hline
\end{tabular}

Note: We report 2SLS estimates using both plant-level (Plant) and firm-level data (Firm) for the model in Section 5 of the main text. We use log NG (coal) to denote the logarithm of the natural gas (coal) price. We use log NG (coal) $\times$ ISO, to denote the interaction of the logarithm of natural gas (coal) price with a dummy that equals one if the entities indicated in columns (1)-(4) participate in ISO/RTO wholesale markets, and zero otherwise. The standard errors in parentheses are clustered by state, year, and month. The asterisks denote statistical significance at $1 \%\left({ }^{* *}\right), 5 \%(* *)$, and $10 \%(*)$, respectively. 
Figure 1: Entities of interest by type of wholesale electricity market

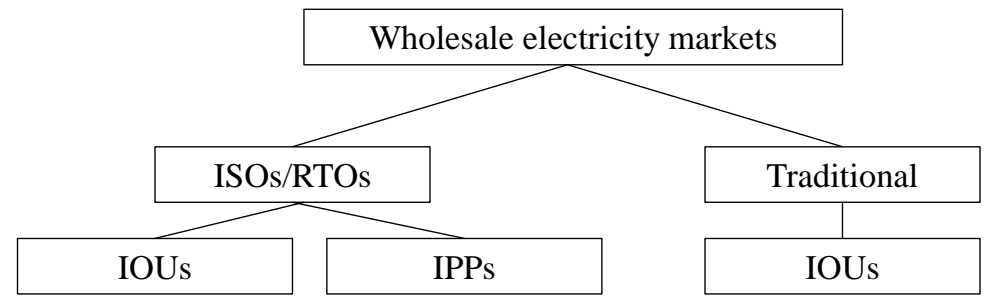

Note: Throughout the paper, we focus on comparisons between investor-owned utilities (IOUs) and independent power producers (IPPs) in wholesale markets coordinated by Independent System Operators/Regional Transmission Owners (ISOs/RTOs), and IOUs in traditional vertically-integrated wholesale markets.

Figure 2: ISO and traditional regional wholesale electricity markets

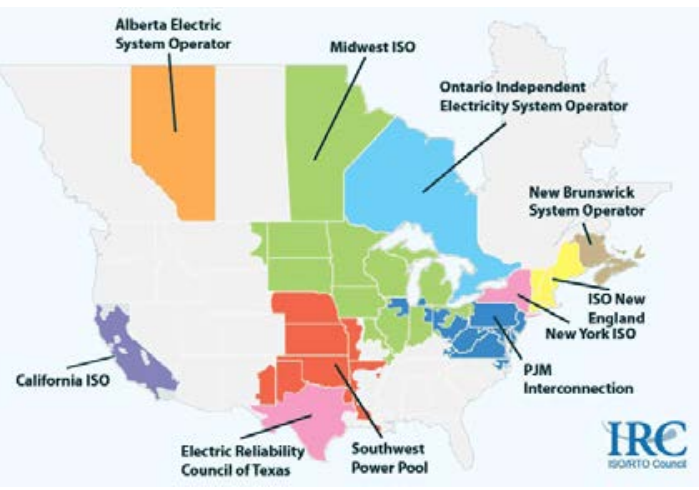

(a) ISOs/RTO markets

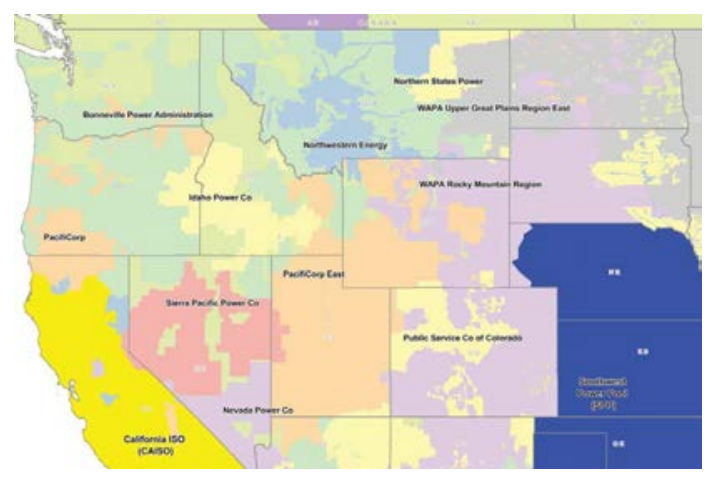

(c) Traditional markets-Northwest

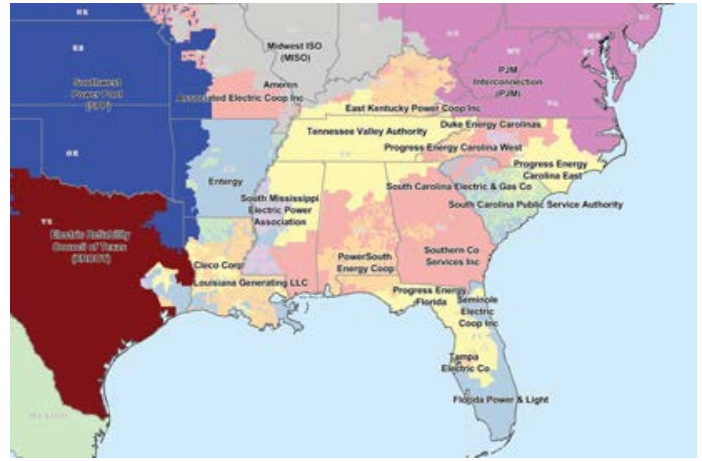

(b) Traditional markets-Southeast

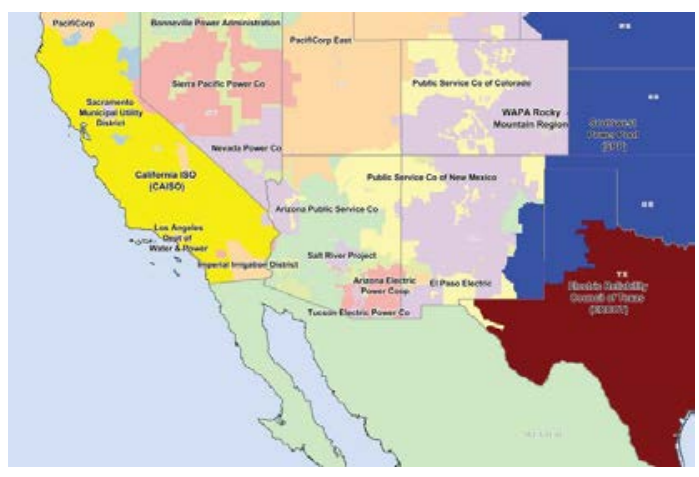

(d) Traditional markets-Southwest

Source: FERC (2012) and New-York ISO 
Figure 3: Fuel costs

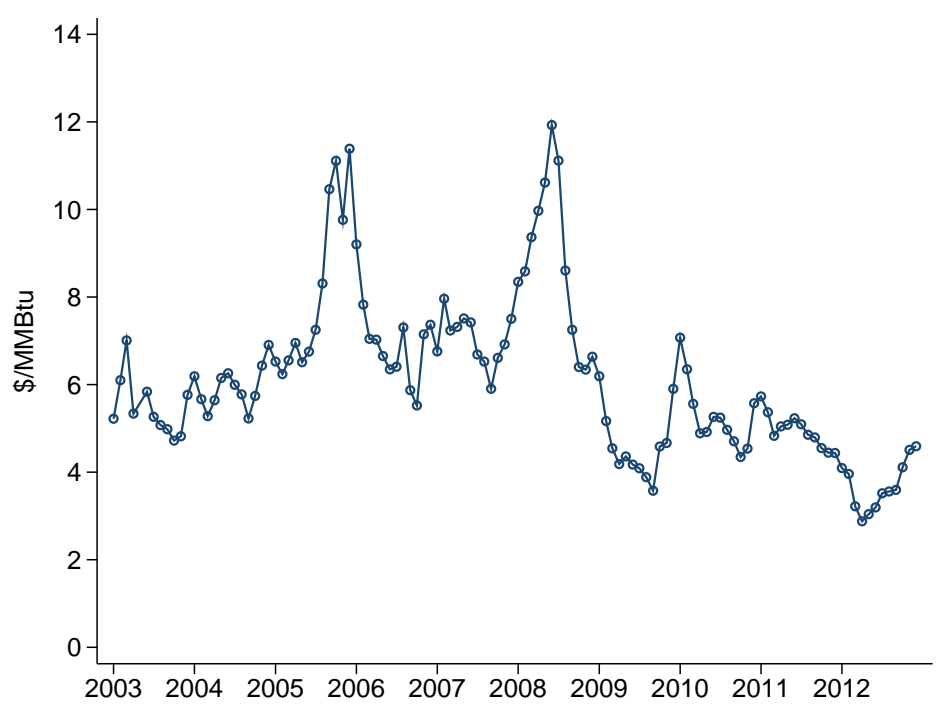

(a) Electric power sector price for natural gas

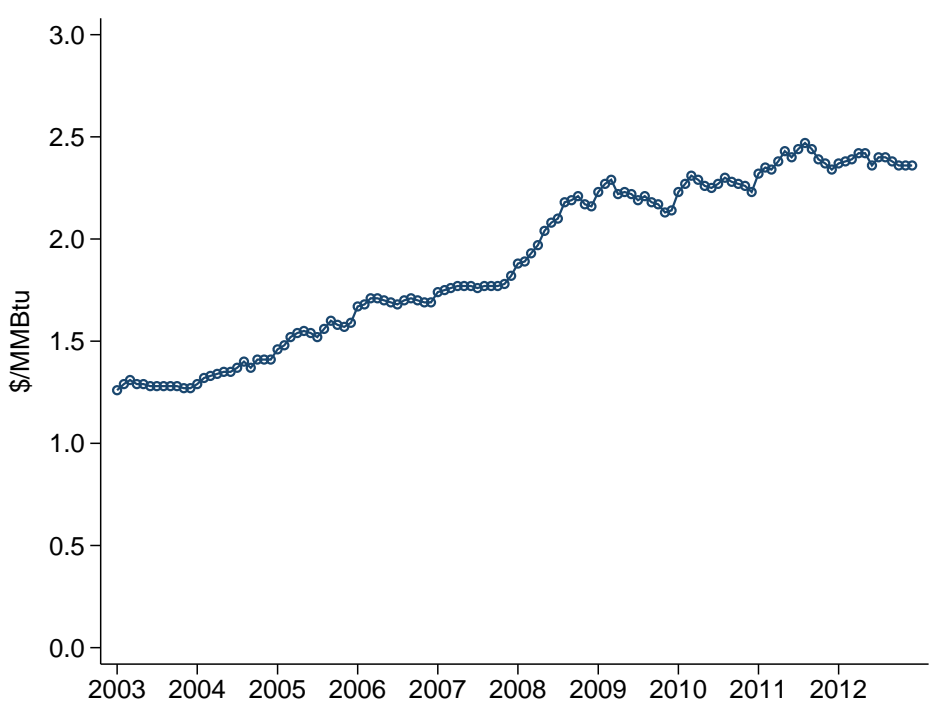

(b) Electric power sector price for coal

Note: We plot monthly natural gas and coal prices $(\$ / \mathrm{MMBtu})$ for the electric power sector using data from the EIA Short Term Energy Outlook Custom Table Builder. ${ }^{44}$

${ }^{44}$ http://www. eia.gov/forecasts/steo/query/index.cfm? 
Figure 4: State-level combined-cycle gas-fired capacity

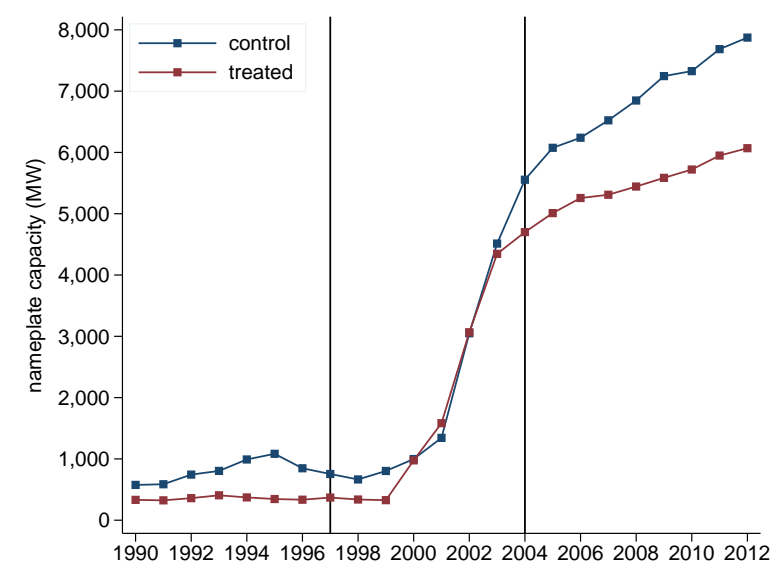

Note: The blue (red) line tracks the average of annual state-level gas-fired nameplate capacity for the control (treated) states. For additional details, see section 4 in the main text.

Figure 5: Kernel density plots of natural gas heat rates with firm-level data

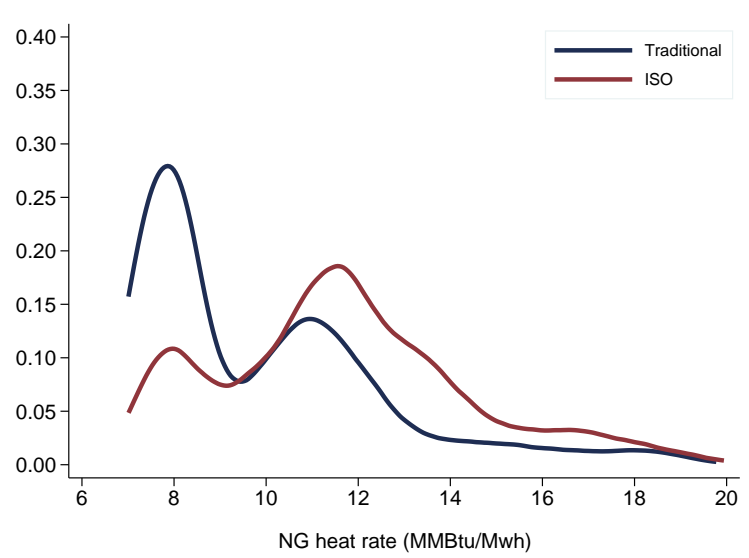

(a) Traditional IOUs vs. ISO IOUs

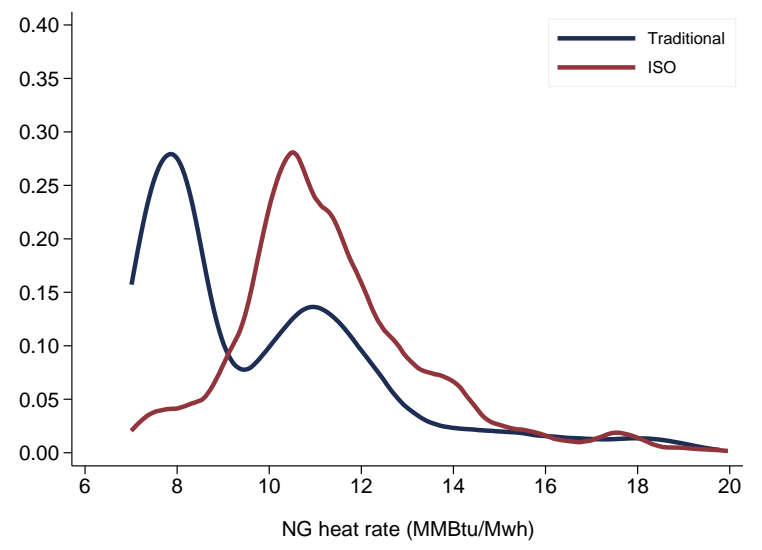

(b) Traditional IOUs vs. ISO IPPs

Note: The kernel density plots are based on the samples in Table 4 that pertain to firm-level data excluding with heat rates below 7 and above $20 \mathrm{MMBtu} / \mathrm{MWh}$. 
Figure 6: Back-of-the envelope (BOE) $\mathrm{CO}_{2}$ emission reduction
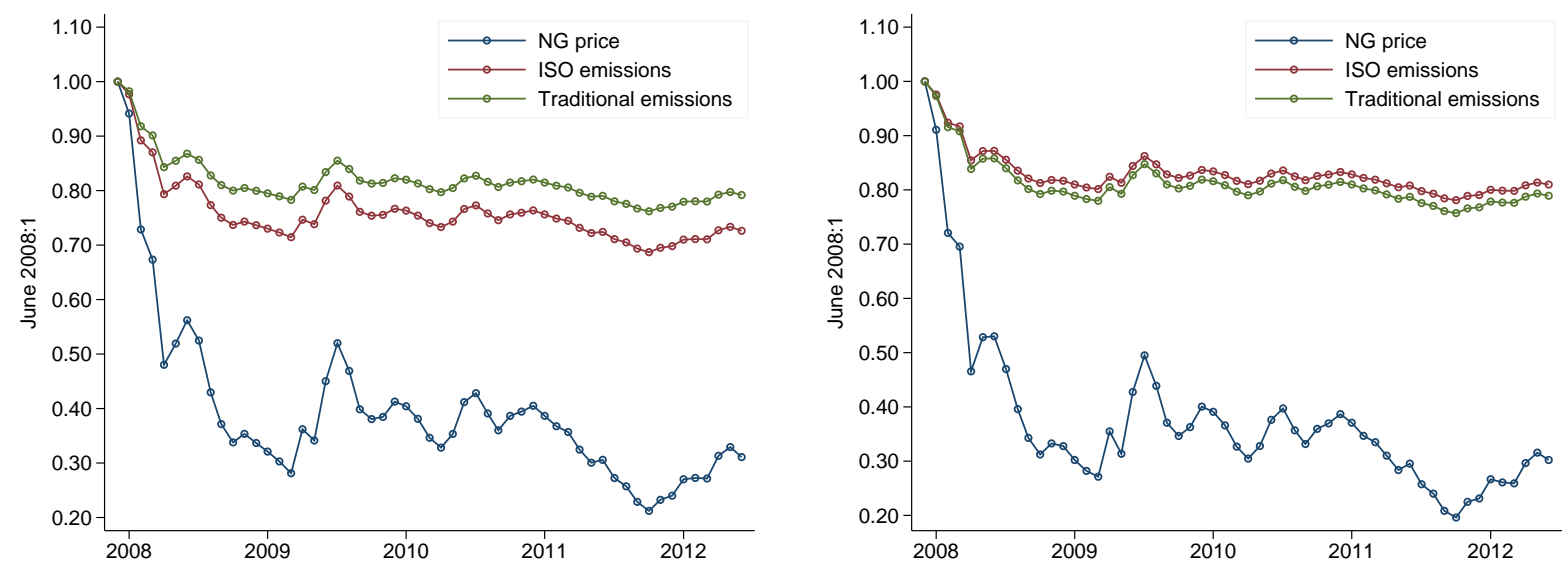

(a) Plant-level data, traditional and ISO IOUs

(b) Plant-level data, traditional and ISO IPPs
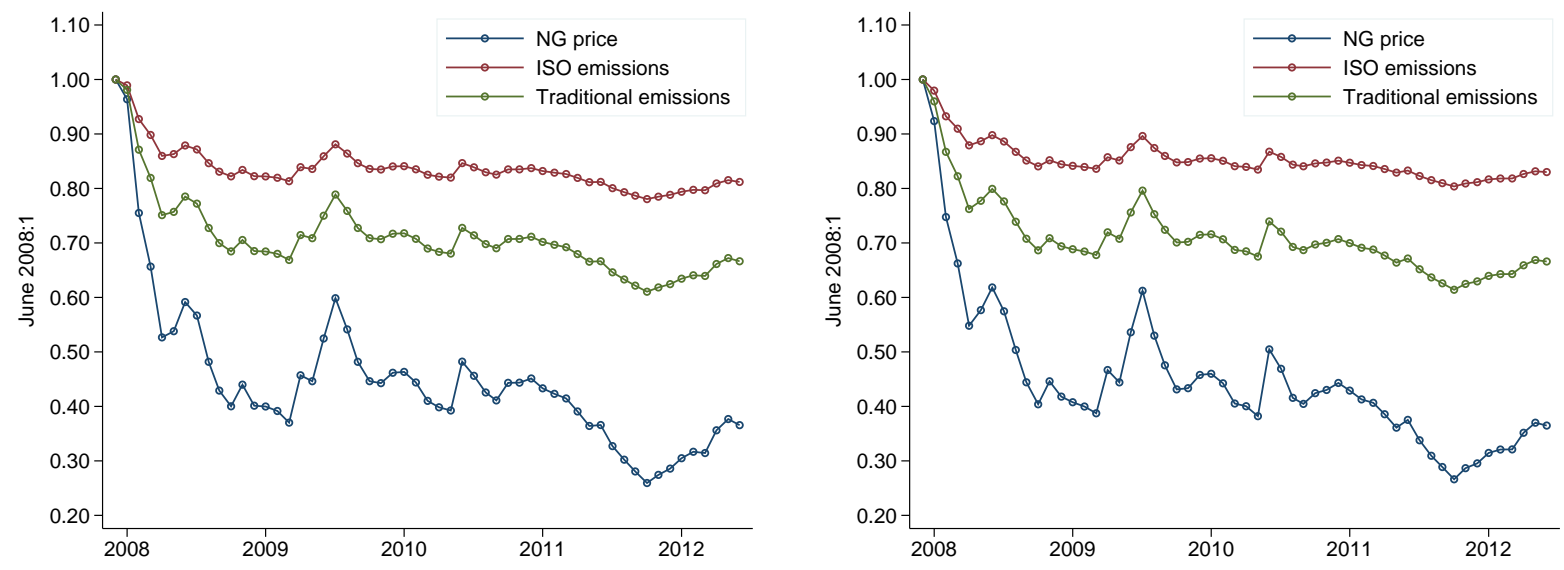

(c) Firm-level data, traditional and ISO IOUs

(d) Firm-level data, traditional and ISO IPPs

Note: The blue line is a monthly price index for natural gas between June 2008 and December 2012 using consumption-weighted fuel prices for the plants in our sample. We translate the index of natural gas prices into an index of $\mathrm{CO}_{2}$ emissions for entities in ISO/RTO (red line) and traditional (green line) markets using the coefficient estimates for natural gas in Table 9. For additional details, see section 5 in the main text. 
Figure 7: Back-of-the envelope (BOE) $\mathrm{CO}_{2}$ emission reduction, eliminating heterogeneity

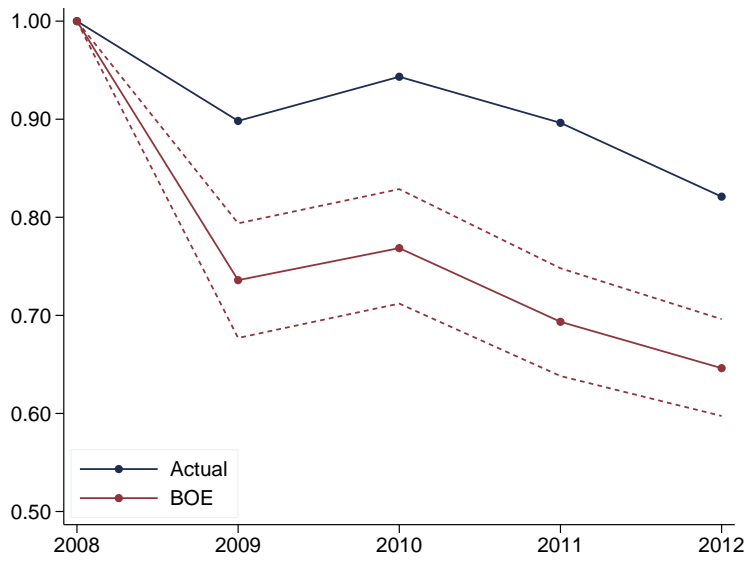

(a) Plant, IOUs

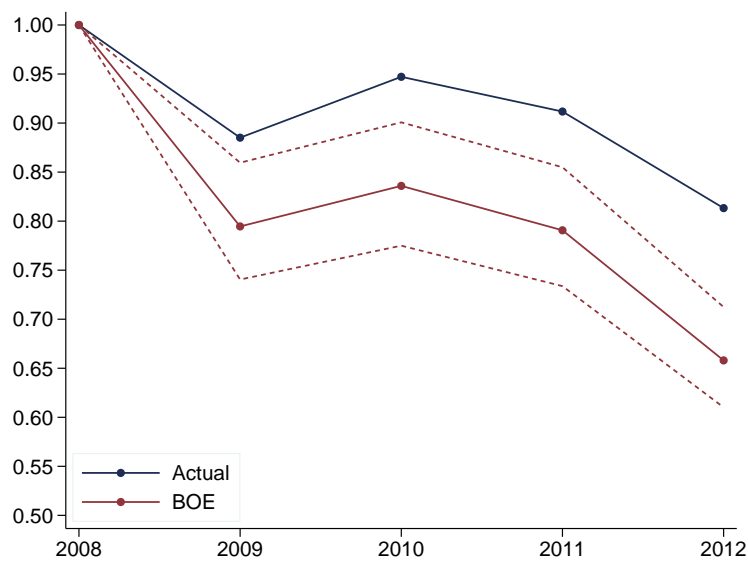

(c) Firm, IOUs

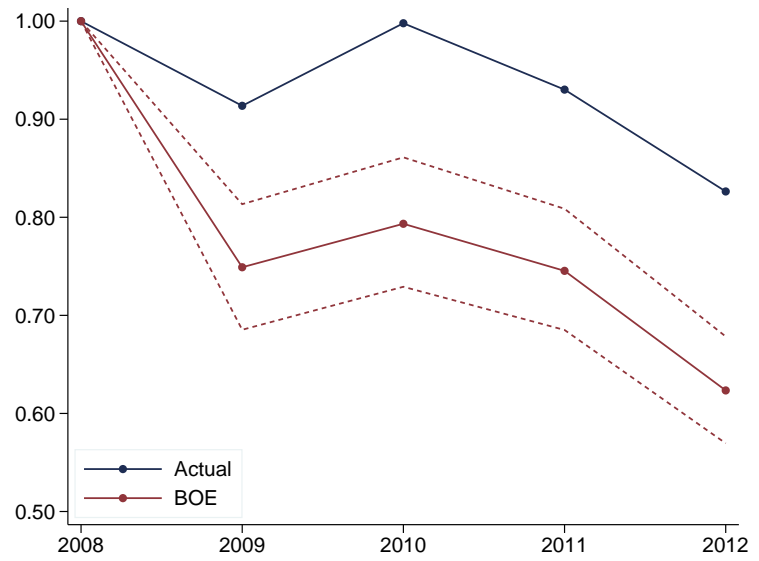

(b) Plant, IPPs

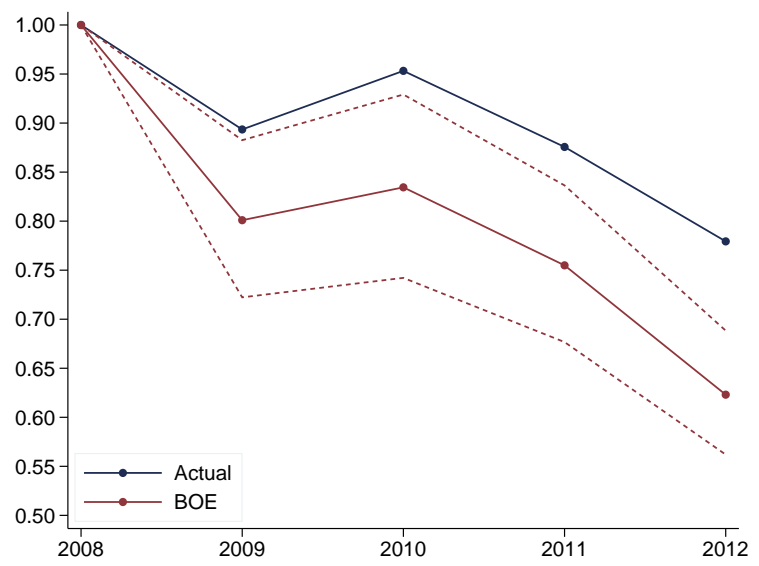

(d) Firm, IPPs

Note: We provide actual (blue line) and BOE (red lines) hypothetical emissions eliminating the heterogeneity in responses to the price of natural gas in Table 9. We do so by setting the interaction of the logarithm of the price of natural gas with the ISO dummy equal to zero. The red short-dashed lines indicate $95 \%$ confidence intervals that have been constructed using non-parametric bootstrap drawing from the estimated residuals. The solid lines correspond to the means of the bootstrap distributions. Our bootstrap makes no correction for heteroskedasticity or clustering. 
A Online Appendix-Not for Publication 


\section{A.1 Data details}

Prior to conditioning on dual-fuel plants, the total number of observations is 256,606 with the number of observations per year lying between 23,296 (2003) and 26,357 (2012). The number of plants per year is between 2,153 (2003) and 2,323 (2012) and does not exhibit notable variation across years. When limited to dual-fuel plants, the sample consists of 40,067 observations, with the number of observations per year varying between 3,634 (2003) and 4,145 (2004 and 2007). The number of plants per year is between 312 (2003) and 348 (2007) without notable variation across years. Additional data requirements for the purpose of the econometric analysis, such as a non-zero gas share of fuel consumption, reduces the number of observations even further to what is reported in the bottom of Table 1 .

Prior to conditioning on dual-fuel firms, the total number of observations is 174,297 . The number of observations per year is between 16,189 (2003) and 18,126 (2006). In addition, the number of firms per year is between 1,458 (2003) and 1,570 (2005). When limited to dual-fuel firms, the sample consists of 33,675 observations, with a number of observations per year that lies between 2,971 (2003) and 3,501 (2006). The number of firms per year is now as low as 255 (2003) and as high as 296 (2007). As in the case of the plant-level data, additional data requirements reduces the number of observations even further to what is reported in the bottom of Table 2 .

\section{A.2 Additional discussion of baseline results}

In the Appendix, we provide a brief discussion of the variables that enter the specification of the linear IV models that we don't report in Table 4.

With plant-level data, the coefficients of the covariates other than prices for the traditional IOUs are essentially identical in both models with plant-level data. Although the quadratic and cubic terms of the generation polynomial are significant, the linear term is not. Operating capacity and seasonal $\mathrm{NO}_{\mathrm{x}}$ prices seem to matter-both enter with a positive coefficient. The number of EGUs equipped with $\mathrm{NO}_{\mathrm{x}} \mathrm{SCR}(+)$ and wet-lime scrubbers (-) are also significant. ${ }^{45}$ The coefficients for the number of EGUs under the CAIRSO2 (-), NBP (-), and TRSO2G1 $(+)$ are also significant. Summer month fixed effects are generally significant. Increased demand for cooling boosts the demand for electricity which in its turn increases the share of gas-fired generation given that intermediate and peaking generation is mostly gas-fired.

\footnotetext{
${ }^{45}$ We use (+/-) to indicate a positive/negative coefficient.
} 
In the case of IOUs, we see significant interactions (with the ISO dummy) for the quadratic and cubic terms of the generation polynomial, the permit prices, the number of EGUs equipped with various abatement technologies (except for the wet-lime scrubbers), as well as the number of EGUs under the ARP. For IPPs, the interactions for the quadratic and cubic terms of the generation polynomial, the seasonal $\mathrm{NO}_{\mathrm{x}}$ permit prices, the number of EGUs with wet-lime scrubbers, and the number of EGUs under the ARP, CAIROS, and the CAIRSO2 programs.

With firm-level data, the coefficients of the remaining covariates for the traditional IOUs are essentially identical in both models. All terms of the generation polynomial fail to be significant. Operating capacity and permit prices seem to matter - all enter with a positive coefficient. Additionally, the number of EGUs equipped with $\mathrm{NO}_{\mathrm{x}} \mathrm{SNCR}(-)$ and dry-lime scrubbers (-) are also significant. Furthermore, the coefficients for the number of EGUs under the CAIRSO2 (-), the TRNOX (-), and the TRSO2G1 (+) programs are significant. Finally, the summer month fixed effects appear to be significant.

In the case of IOUs, we see significant interactions (with the ISO dummy) for the $\mathrm{SO}_{2}$ permit prices (both negative), the number of EGUs with dry lime scrubbers $(+)$ and PM $(+)$ abatement technologies, as well as the number of EGUs under the ARP $(+)$, the CAIRSO2 $(-)$, the NBP (-), and the TRSO2G2 programs. For IPPs, the interactions with the terms of the capacity, the permit prices (both negative), the number of EGUs with dry-lime scrubbers $(+)$, and the number of EGUs under the ARP (-), and the TRSO2G1(+) programs, are all significant.

\section{A.3 Additional explanations for response heterogeneity}

The difference in incentives to reduce costs between traditional and ISO IOUs may explain the difference in their responses to fuel prices. Discussions with an individual representing a utility with operations in ISO and traditional markets corroborated this explanation. ${ }^{46} \mathrm{He}$ explained that in ISO markets his company is able to keep only a part of cost savings for power plants that generate in excess of their required demand - the remaining cost savings are passed directly to the final customers. In contrast, in traditional markets, the utility is the residual claimant to any costs savings taking place between rate hearings. ${ }^{47}$ Further-

\footnotetext{
${ }^{46}$ We held this discussion in late winter of 2013. We maintain the anonymity of the individual per his request.

${ }^{47}$ Regulatory lags in rate hearings offers an incentive for the utilities to reduce costs since they reap the profits between hearings (e.g., Joskow (1974)). Fabrizio et al. (2007) argue that frictions in in cost-of-service regulation have limited impact on the incentive for cost-reducing efforts apart from periods of rapid nominal
} 
more, based on conversations we have had, ISO IOUs hedge their fuel purchases more than traditional IOUs. Actually, utility commissions encourage utilities to hedge their fuel costs. As a result, they are insulated from short-term price fluctuations, and, hence, their output is insensitive to short-term changes in fuel prices. Unfortunately, data availability precludes us from providing empirical support for this explanation.

Finally, we checked whether the different responses to fuel prices for traditional and ISO IOUs could be attributed to a different mix of own generation and wholesale power purchases to serve their demand. IOUs may respond less to fuel prices if own generation accounts for a smaller fraction of their source of electricity. Using data from EIA-861, we calculated the fraction of IOUs' total disposition from wholesale power purchases (MWh) . ${ }^{48}$ Using annual data for 17 traditional and 30 ISO IOUs with dual-fuel plants for 2003-2012, wholesale purchases accounted for $19 \%$ of traditional IOUs' disposition, on average, oscillating between $16 \%$ and $22 \%$. The same figures for ISO IOUs were, $26 \%, 29 \%$, and $32 \%$, respectively. Hence, the fact that wholesale power purchases account for a larger fraction of the source of electricity for ISO IOUs compared to traditional IOUs may also explain the fact that they respond less to fuel prices.

cost inflation.

${ }^{48}$ EIA-861 follows the terminology total sources and total disposition. Generation and purchases from electricity suppliers are among sources. Sales to ultimate consumers and sales for resale are part of disposition. 